\title{
Deriving trends in life expectancy by the National Statistics Socio- economic Classification using the ONS Longitudinal Study
}

Brian Johnson Office for National Statistics

\section{Abstract \\ Background}

Health inequalities among socio-economic groups are well documented. One of the measures used to track inequalities over time is the series 'Trends in life expectancy by social class, 1972-2005', on the Office for National Statistics website. In 2001 the National Statistics Socio-economic Classification (NS-SEC), replaced Registrar General's social class (RGSC) for the purposes of official statistics. This paper describes the challenges involved in producing an analogous series of trends in life expectancy by NS-SEC to that by RGSC, the approach adopted, and publishes the first results of the new series.

Methods

NS-SEC was devised in the 1990s and introduced in 2001. Like RGSC, it is an occupationbased measure. In order to produce a series of trends over more than 20 years based on NS-SEC, it is necessary to classify people according to NS-SEC based on their occupation at the 1981 and 1991 Censuses and then to measure subsequent mortality rates for different classes. The 1981 Census preceded the construction of the NS-SEC classification system by nearly 20 years, and there was no recognised way of classifying 1981 Census respondents by NS-SEC. This paper describes how an approximation to allow such a classification was derived. The ONS Longitudinal Study was used to provide the data from which mortality and survival rates by NS-SEC class could then be estimated.

\section{Results}

The results are presented in terms of life expectancy at birth and at age 65 by five-year calendar periods, from 1982-86 to 2002-06. A social gradient was found using NS-SEC, similar to the one found using RGSC. For most classes for all periods studied, life expectancy improved for both males and females but inequalities persisted between classes. There was a difference of around six years for males between the most and least advantaged classes in expectation of life at birth and about four years for females in the 
period 2002-06. The estimates suggested a widening of inequalities over the study period for men, which appeared to end after 2001. For women, no overall trend could be detected, but there were no signs of any narrowing of the gap in the most recent period.

\section{Conclusions}

NS-SEC can be used to provide medium-term trends in life expectancy by occupation based class, which will be capable of extension over time, although certain approximations are necessary. It is important that work should continue on investigating other means of classification, particularly for women, for example based on educational attainment and on household rather than individual-based measures. 


\section{Contents}

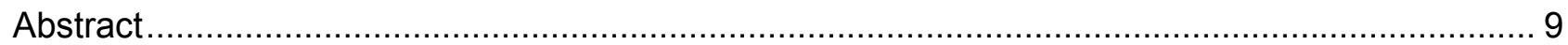

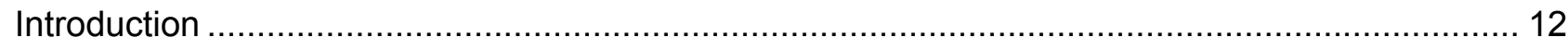

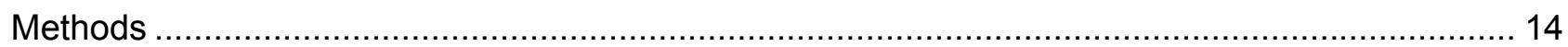

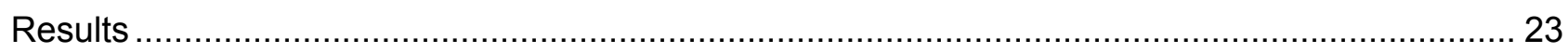

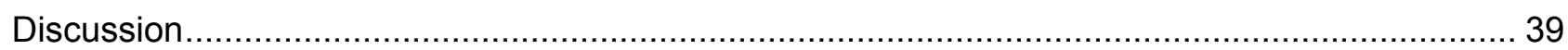

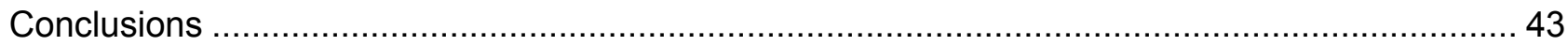

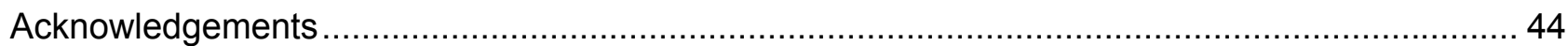

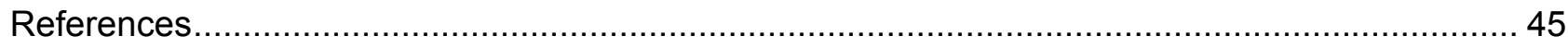

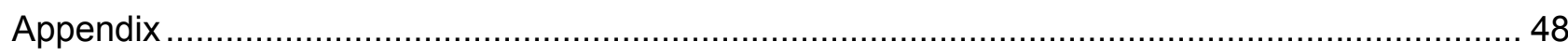

\section{List of Figures}

Figure 1 Life expectancy by NS-SEC class, males at birth . 30

Figure 2 Life expectancy by NS-SEC class, females at birth 


\section{List of Tables}

Table 1 Cross-tabulation of death registrations in 1993 classified according to NS-SEC based on 1981 occupation (NS-SEC80) and 1991 occupation (NS-SEC90) ........... 24

Table 2a Life expectancy by NS-SEC class, males at birth ............................................... 26

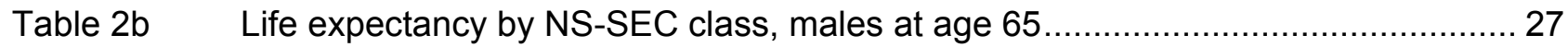

Table $3 \quad$ Change in life expectancy at birth and at age 65 by NS-SEC, males ................... 29

Table $4 \quad$ Life Expectancy at birth and at age 65 by social class, males............................... 31

Table 5a Life expectancy by NS-SEC class, females at birth......................................... 33

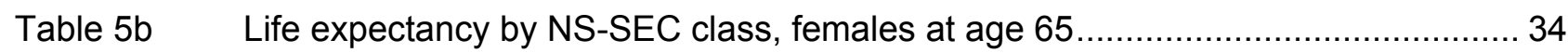

Table $6 \quad$ Change in life expectancy at birth and at age 65 by NS-SEC, females.................. 36

Table $7 \quad$ Life Expectancy at birth and at age 65 by social class, females............................ 38

Table A1a Life expectancy by NS-SEC class, males at birth, using a 'combined' classification

Table A1b Life expectancy by NS-SEC class, males at age 65, using a 'combined' classification 49

Table A2a Life expectancy by NS-SEC class, females at birth, using a 'combined' classification

Table A2b Life expectancy by NS-SEC class, females at age 65, using a 'combined' classification

\section{Introduction}

Health inequalities among socio-economic groups are well documented. Since 1921 when the Registrar General's social class schema was introduced for adults, in the form that was to survive almost to the end of the century (Rose, 1995), differences in mortality rates among classes have been observed. These differences have persisted over time and have tended to prove resistant to the attempts of policymakers to reduce them. Influential reports on the subject have been produced by (among others), Black (1980), Acheson (1998) and most recently Marmot (2010) in 'Fair Society, Healthy Lives (The Marmot Review).' Together with policy recommendations, the latter provides a comprehensive overview of the situation in England and a wealth of references.

The conventional method for estimating mortality rates by class has been to use the decennial census of population to provide age and socio-economically stratified denominators, and death registrations coded by occupation for years close to the census to provide numerators. (Up to and including 1991 only a sample of census households had their occupants coded by occupation).

This method, while producing consistent findings over a long period, had a number of drawbacks: 
Firstly, there are differences in the method of recording of occupation at death and at the census, and secondly, mortality rates can only be estimated at working ages, since occupation is not coded at the census for people over 74 years of age and sparsely coded between the ages of 65 and 74 . (OPCS, 1978). Given that a decreasing minority of deaths occur below age 65 , it became increasingly important to have available a means of classifying older people to NS-SEC using occupation recorded earlier in their lives. In this way, life expectancy can take account of life course exposures of those dying at older ages.

These shortcomings constituted a major part of the motivation for creating the ONS (formerly OPCS) Longitudinal Study (LS). This has eliminated numerator-denominator bias and allowed the classification of sample members according to their census characteristics often at working age, and the subsequent follow up to measure death and survival rates for each class over time. This allows the computation of age-specific mortality rates at older ages. This in turn has allowed the computation of life tables for different socio-economic classes to be produced.

'Expectation of life by social class' was first published by Hattersley (1997) and developed and updated by Donkin et al. (2002) and makes use of the LS, together with the continuity provided by the occupation-based RG social class classification. The series has been extended at intervals since then, the most recent update being in 2007, when the last period for which estimates were published was 2002-05.

In 2001 RG Social Class was replaced by the National Statistics Socio-economic Classification (NS-SEC) for the purposes of official statistics. It was possible to extend the series on trends in life expectancy by RG social class by a few years following the census, but it was clear that, since neither deaths nor census returns were to be coded by RGSC any longer, it was imperative to develop a new series using NS-SEC.

Analyses of mortality rates by NS-SEC have been undertaken using death registrations as numerators and figures based on the 2001 Census population as denominators in 'cross-sectional' studies (White et al., 2007, Langford and Johnson, 2009), but these are only possible for ages up to 64 and therefore are not suitable for estimating life expectancy.

The key component of this study was to provide an NS-SEC code for occupations recorded at the 1981 Census using the occupational coding undertaken the time. If such a classification could be produced, it would be possible to undertake a prospective study whereby those present at the 1981 Census could be classified at, or shortly after working age, and then followed up through to the 2000s. This step was particularly important for those in retirement age in the 1990s and 2000s, since the 1991 or 2001 Census may well not have captured their occupation.

The main difficulties with this approach were:

- conceptual - the change in the nature of work and contracts of employment over time make the application of NS-SEC in 1981 problematic

- practical - the lack of appropriate granularity in the 1981 Census classification system to allow mapping to modern occupation codes 
It would not have been cost effective to go back to the original census returns and attempt to recode them, so some kind of 'bridge-coding' was necessary

This article describes how ONS went about constructing this bridge and the methodology adopted to overcome the problems of discontinuity. It addresses some questions related to the attribution of any socio-economic classification system, particularly for women, and presents the first results for 'life expectancy by NS-SEC'.

\section{Methods}

This section describes the NS-SEC in more detail, the reasons why it replaced the Registrar General's social class classification in official statistics, and the analytical approach adopted in this article. The key component of the analysis is the creation of an NS-SEC classification using data from the ONS Longitudinal Study (LS) relating to the 1981 Census. This process is described in detail following a brief overview of the NS-SEC and the data sources used.

\section{The National Statistics Socio-economic Classification}

Registrar General's social class based on occupation remained almost unchanged in structure for most of the 20th Century. It was based on a hierarchical view of occupational skills and general social standing, and above all, the divide between non-manual and manual occupations. While proving effective in discriminating between classes in empirical studies, changes in economic structure, such as the decline in manufacturing and the growth of the service sector, have provided practical reasons for dispensing with the classification in official statistics. Just as important, it was criticised for having no universally agreed underlying concept, (Rose \& Pevalin, 2003), and therefore it was claimed that it is not clear how to interpret the meaning of differences between classes revealed by measuring mortality or other characteristics.

The conceptual basis for the NS-SEC is the structure of employment relations operating in modern developed economies (Rose \& Pevalin, 2003), based on a schema developed by Goldthorpe (1997). Occupations are differentiated in terms of reward mechanisms, promotion prospects, notice periods and job security. Those occupations exhibiting a high level of such characteristics are said to be operating on a 'service contract'. Those with the least of these attributes are said to be operating under a 'labour contract'. While not designed as a hierarchy, there are differences in social advantage across the classes. The most advantaged NS-SEC groups (higher managerial and professional occupations), typically exhibit personalised reward structures, have good opportunities for advancement, relatively high levels of autonomy within the job, and are relatively secure. These attributes tend to be reversed for the most disadvantaged group (routine occupations).

Box 1 shows the NS-SEC analytic class breakdowns used in this analysis, and provides examples of the occupations included in each class. 


\section{Box 1 National Statistics Socio-economic Classification Analytic classes*}

\section{Analytic class}

1.1 Large employers and higher managerial

$1.2 \quad$ Higher professional

$2 \quad$ Lower managerial and professional

$3 \quad$ Intermediate

$4 \quad$ Small employers and own account workers

Lower supervisory and technical

$6 \quad$ Semi-routine

$7 \quad$ Routine 
An individual can be assigned to an NS-SEC class based on their occupation, employment status and the size of their organisation, (employment status relating to whether they are an employer, a manager, supervisor or ordinary employee). A version of NS-SEC can be derived from occupation and employment status alone. This is known as 'reduced NS-SEC' and differs in terms of its typical distribution among NS-SEC classes by about two per cent (ONS NS-SEC User Manual 2002). Reduced NS-SEC was used throughout the following analysis since size of establishment is not available for all sources of information used in this study, (for example father's or mother's occupation based classification at the birth of a child). Reduced NS-SEC was also used in previously published cross-sectional analyses of mortality rates by NS-SEC (White et al., 2007), since size of establishment is not included in the data collected at death registration.

All people for whom there is sufficient information at a census on their occupation and employment status can be assigned an NS-SEC 'analytic' category such as those which appear in Box 1. The lookup table, which allows the transformation of combinations of occupation and employment status, is known as a 'derivation matrix'. A section of a derivation matrix for NS-SEC in 2001 is shown in Box 2. Every decade for which NS-SEC is to be assigned requires a derivation matrix which converts the contemporary occupation definitions and employment statuses into NS-SEC classes. 


\begin{tabular}{|c|c|c|c|c|c|c|}
\hline \multirow[b]{2}{*}{ SOC2000 } & \multicolumn{6}{|c|}{$\begin{array}{l}\text { Extract of derivation matrix for NS-SEC using occupation } \\
\text { ) and employment status to determine analytic class }\end{array}$} \\
\hline & Standard Occupational Classification 2000 & Employers & $\begin{array}{r}\text { self- } \\
\text { employed }\end{array}$ & Manager & visor & Employee \\
\hline Occupa & tional Unit Group & & & & & \\
\hline 1111 & Senior officials in national government & 1.1 & 1.1 & 1.1 & 1.1 & 1.1 \\
\hline 1112 & $\begin{array}{r}\text { Directors and chief executives of major } \\
\text { organisations }\end{array}$ & 1.1 & 1.1 & 1.1 & 1.1 & 1.1 \\
\hline 1113 & Senior officials in local government & 4 & 4 & 1.1 & 1.1 & 1.1 \\
\hline 1114 & Senior officials of special interest organisations & 4 & 4 & 2 & 2 & 2 \\
\hline 1121 & Production, works and maintenance managers & 4 & 4 & 1.1 & 1.1 & 1.1 \\
\hline 1122 & Managers in construction & 4 & 4 & 2 & 2 & 2 \\
\hline 1123 & Managers in mining and energy & 4 & 4 & 1.1 & 1.1 & 1.1 \\
\hline 1131 & Financial managers and chartered secretaries & 1.2 & 1.2 & 1.1 & 1.1 & 1.1 \\
\hline 1132 & Marketing and sales managers & 4 & 4 & 1.1 & 1.1 & 1.1 \\
\hline 1133 Purcha & sing managers & 4 & 4 & 1.1 & 1.1 & 1.1 \\
\hline 1134 & Advertising and public relations managers & 4 & 4 & 1.1 & 1.1 & 1.1 \\
\hline 1135 & Personnel, training and industrial relations managers & 4 & 4 & 1.1 & 1.1 & 1.1 \\
\hline 1136 & $\begin{array}{r}\text { Information and communication technology } \\
\text { managers }\end{array}$ & 4 & 4 & 1.1 & 1.1 & 1.1 \\
\hline 1137 & Research and development managers & 1.2 & 1.2 & 1.1 & 1.1 & 1.1 \\
\hline 1141 Quality & assurance managers & 4 & 4 & 2 & 2 & 2 \\
\hline
\end{tabular}

Source: NS-SEC User Manual, Office for National Statistics (2002)

For those who cannot be assigned an occupation-based functional NS-SEC category, there are certain other categories, such as 'full-time student', 'never worked' 'long-term unemployed' 'inadequately described'. These are known as 'residual' categories. Residual categories are reported in this analysis in aggregate as 'Unclassified', both for completeness and because a substantial proportion of them are likely to be among the most deprived, having no occupation assigned. The NS-SEC sub-divisions, such as 'Never worked' and 'Long-term unemployed' were not available at censuses before 2001. As a result, 'Unclassified' constitutes a heterogeneous category, the composition of which may change over time. Consequently, it was decided to restrict the measurement of trends in inequality to the occupation-based classes.

Further aggregations of the classes are possible, and a useful summary measure is 'condensed' NS-SEC which consists of: 
1. Managerial and professional (consisting of analytic classes 1.1, 1.2 and 2, the 'service contract' groups.

2. Intermediate (consisting of analytic classes 3 and 4)

3. Routine and manual (consisting of analytic classes 5, 6 and 7, the 'labour contract' groups)

These groupings are larger and less volatile from one time period to the next than the more refined analytic classes, and sometimes give a clearer picture of trends and turning points in inequalities. For this reason, the analysis was carried out both for the seven analytical classes and the condensed NS-SEC.

\section{Data Sources for analysis}

\section{The ONS Longitudinal Study (LS):}

The LS contains linked census and vital event data for one per cent of the population of England and Wales. Information from the 1971, 1981, 1991 and 2001 Censuses has been linked together, along with information on events such as births, deaths and cancer registrations. The unique advantage of this data source for the type of analysis described in this article is that sample members can be classified according to their census characteristics, often at working age, and then followed up to measure death and survival rates for each class over time.

This allows the computation of age-specific mortality rates at older ages based on occupational data recorded at or shortly after working age, which is not possible using a cross-sectional approach, since occupation is not coded at the census for people over 74 years of age. Father's and mother's occupation is recorded for children present at a census and at birth for new babies. The LS has occupation and employment status coded for those present at censuses from 1971 to 2001 and NS-SEC for those present at the 2001 Census.

\section{Derivation matrices for NS-SEC.}

The matrix developed for the 2001 Census producing reduced NS-SEC is available from the NSSEC user manual (ONS 2002). An approximation to NS-SEC, derived using the SOC90 occupation classification also exists and can be found in the same publication. This allows the NS-SEC classification of LS members at the 1991 Census, or for the parents of children born in the decade between the 1991 and 2001 Censuses.

As yet there is no derivation matrix for NS-SEC using the 1981 occupational classification. Therefore, the main component of the current study was to produce and validate such a matrix for use with LS data so that members may be classified at the 1981 Census or at birth between 1981 and 1991. 


\section{Analytical approach}

As a result of changes in economic structure and the nature of occupations over time, the occupational classification system is reviewed every 10 years. Box 3 shows the nomenclature for the occupational and socio-economic classifications used at each census since 1981.

\begin{tabular}{|lll}
\hline $\begin{array}{l}\text { Box } 3 \\
\text { economic classifications used at each census since } 1981\end{array}$ \\
$\begin{array}{lll}\text { The nomenclature for the occupational and socio- } \\
\text { Occupational } & \begin{array}{l}\text { Socio-economic } \\
\text { Classification }\end{array} \\
1981 & \text { Classification } & \text { Registrar General's Social Class (RGSC) } \\
1991 & \text { CO80 } & \text { RGSC } \\
& \text { NS-SEC90 } \\
2001 & \text { NOC2000 } & \text { NS-SEC }\end{array}$
\end{tabular}

The 1991 and 2001 derivation matrices were produced in part via detailed analysis of specially commissioned questions included in the 1996/97 Labour Force Survey (Rose and Pevalin (2003).

It would be neither practical nor economically viable to repeat this detailed analysis for the census of 1981. However, the existing degree of linkage between the 1981 occupational classification system (known as CO80) and the SOC90 classification used for the 1991 Census, from which NSSEC90 can be derived, is sufficient to allow an approximation for NS-SEC using 1981 occupations.

Hence the NS-SEC90 derivation matrix of occupation and employment status could be used as a template from which an 'NS-SEC80' matrix can be derived. If there was a unique mapping between CO80 (1981) occupations and the SOC90 ones, this would be straightforward. However changes in the occupation classification scheme over the 10-year period result in some degree of discontinuity. The Standard Occupational Classification, Volume 3 (OPCS 1991) estimated that 56 per cent of a 0.5 per cent sample of occupations drawn from the 1981 Census population had a directly comparable SOC90 code. A further 12 per cent was capable of mapping to a SOC90 code if CO80 codes were aggregated. This left roughly 30 per cent of the 1981 population not capable of mapping to a unique SOC90 code (see Box 4). 


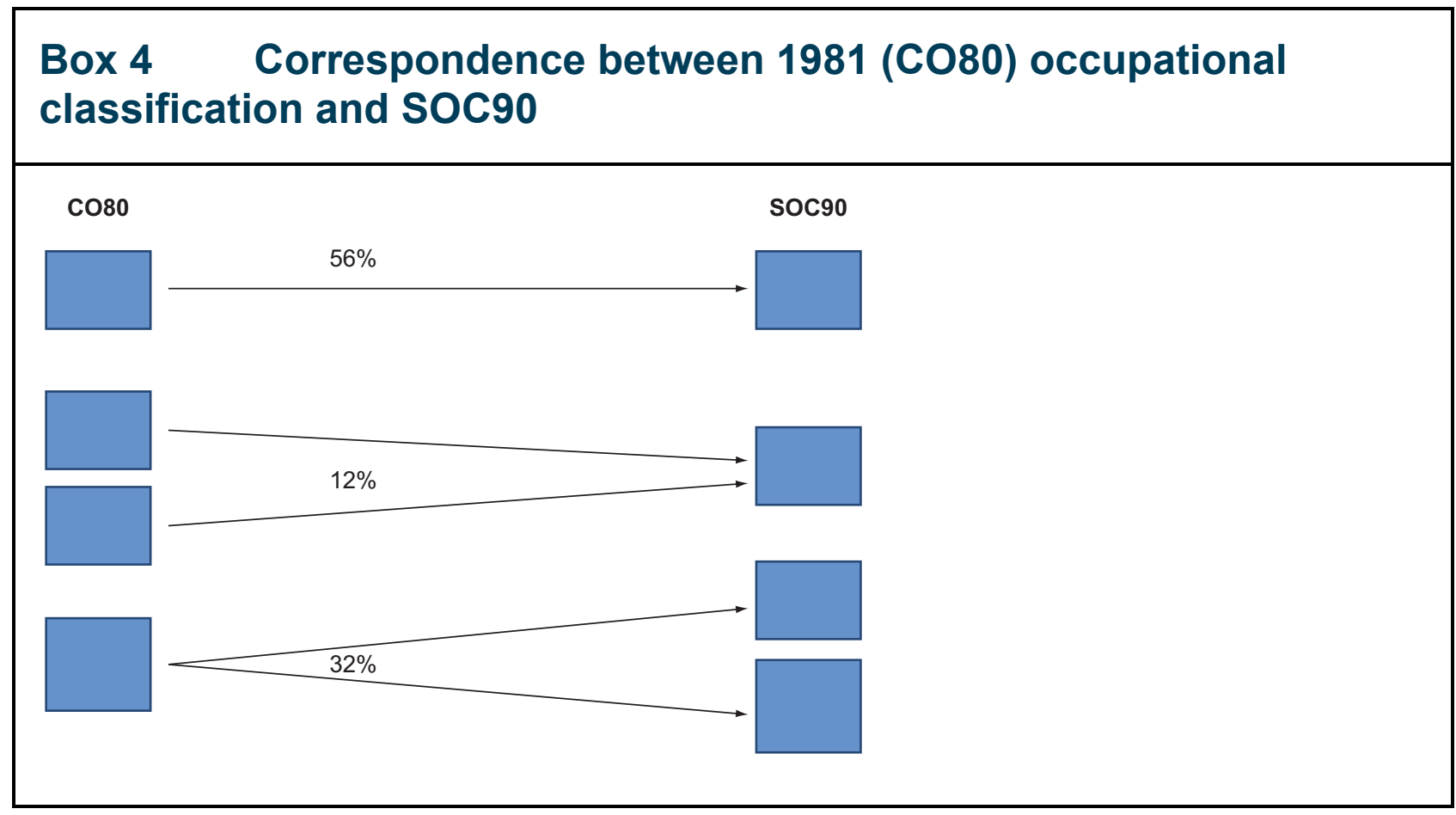

In the current study it is the 1981 Census population which needs to be mapped to a SOC90 code and via that, to an NS-SEC class - it does not matter if it is not possible to map SOC90 categories to unique CO80 ones, (Box 4). That is to say, it is occupations in 1991 for which there is no 1981 equivalent, which provided the problem (for example: Software engineers who were grouped together with Computer systems and data processing managers and with Computer analyst/programmers in 1981).

There were three categories of $\mathrm{CO} 80$ occupation:

1. Those which mapped directly to a single SOC90 code

2. Those which mapped to more than one SOC90 codes, but all relevant SOC90 codes produced a unique NS-SEC analytic class when combined with employment status

3. Those which mapped to more than one SOC90 code, at least two of which were associated with different NS-SEC classes (even when employment status was the same)

Only the third category presents problems, since the other two produce unique analytic classes.

The scale of the problem could be tested empirically, since the 1991 Census occupations were dual coded on the LS both to the 1981 and 1991 classifications. For each 1981 occupation code, where there was no unique mapping to SOC90, the population assigned to each analytic NS-SEC class could be measured. This allowed the measurement of the size of the population for which the combination of 1981 occupation and employment status did not uniquely determine NS-SEC class.

For example, CO80 occupation number 43, (nurse administrators and nurses), maps to SOC90 occupations 340 (nurses), 640 (assistant nurses, nursing auxiliaries) and 643 (dental nurses). The number in the sample having this occupation and an employment status of employee as follows: 
NS-SEC

$\begin{array}{lr}\text { Class } 2 \text { (lower professional) } & 4,461 \\ \text { Class } 3 \text { (intermediate) } & 1,857 \\ \text { Class } 6 \text { (semi-routine) } & 240\end{array}$

(The heterogeneity of this CO80 occupation group and the problems it posed for social classification was referred to by Elias (1997)). The simplest approach is to choose the NS-SEC class with the greatest population (in the above case class 2 ), for that combination of occupation and employment status and apply that class in the appropriate cell of the derivation matrix. In cells where the ratios between the most and least represented NS-SEC classes were very high (10 to 1 or more) and the minority group had less than 10 members in the sample, this approach was used.

However, to use this simple majority method in the above instance would result in the incorrect assignment to NS-SEC of a substantial number of sample members. Additional information, which was available in 1981 and could be empirically tested using the dual coded 1991 Census data, was sought for these problematic cells of the matrix. Only 'industry code' and 'industry size' were found to discriminate in cells where there were multiple potential NS-SEC classes. In the example given above, nearly all the NS-SEC class 6 population related to dental nurses. These were not separated from other nurses by $\mathrm{CO} 80$, but where the industry code was 'dental practices', almost all the population was assigned to class 6 in 1991. Where industry code was found to be useful in this context, it was used to adjust the cells of the derivation matrix. The impact of industry code on the precision of the classification is reported in the Results section below.

A further test of validity of the method was performed by applying it to the dual coded deaths registrations for 1993. In each case it was possible to determine the proportion of erroneous classifications made using the 1981 derivation matrix constructed as described above.

\section{Assignment of NS-SEC class}

Once the 1981 derivation matrix was produced, it was possible to classify LS members present at 1981 by their own or by their spouse's, father's or mother's class, if the occupation of any of the latter was recorded at the census.

The standard approach to assigning class for the 'life expectancy by social class' series was to classify sample members on entry to the study, after Hattersley (1997). Where possible, an individual's own NS-SEC class was used. For those with no assigned occupation and who were married, spouse's class was used. For those who were children at a census, father's class was used, and failing that mother's. For new births where the child was not recorded at the following census, father's class at birth was used, and failing that, mother's. Immigrants were assigned an NS-SEC class at the first census at which they were present. If they were not present at any census they were excluded from the study since there was no way of assigning a class to them and they may have gone abroad without this fact being recorded, and therefore no longer 'at risk' (Johnson and Blackwell, 2007). If none of this information resulted in the sample member being assigned a class, they were coded as 'Unclassified'

The main rationale for assigning class at the earliest possible point after entry to the study is that, in a prospective study, it is important that the assignment of class is not influenced by the fact of 
death or survival. An additional benefit is that the longer the period of follow up, the less prevalent are health selection effects. These occur when some sample members cannot be classified by occupation owing to poor health when assignment of class takes place. These members have a relatively high probability of dying soon after assignment of class. This health selection out of the labour market disproportionately affects Routine and manual occupations, so a bias may be introduced where those in the least advantaged classes appear to have a lower mortality rate relative to others, in the period immediately following classification, than they otherwise would have done (Fox et al., 1985).

The earlier that assignment takes place, and therefore the longer the period of follow up, the less effect selection will have upon the estimates, since those sample members who were sick at the point of assignment will tend either to die or to recover over time.

There is also some evidence that socio-economic position in early years is more influential on health outcomes than status in later life (The Black Report 1980, White et al., 2005).

Taking into account the above and the history of these estimates, the following approach was decided upon: NS-SEC was derived for sample members and their spouses for each census between 1981 and 2001 at which they were present, or at birth for children born after census day in 1981, based on their father's or mother's class, if available. Therefore, for a given sample member, there was frequently more than one class that they could potentially be assigned to. The next stage was to apply a set of rules assigning class to each sample member.

The method of assignment followed the standard approach described above.

A second method classified people by the most advantaged of their own and their spouse's class, and children by the most advantaged of their father's and mother's class. This 'combined' approach is based on a concept of Erikson (1984) and was used in the cross-sectional study of inequalities in mortality rates of women of working age by NS-SEC (Langford and Johnson, 2009). It perhaps provides a more relevant assessment of a person's socio-economic position than one based on primacy of one's own class. While this is not a true 'household' measure of socioeconomic position, it is useful to determine the sensitivity of the life expectancy estimates to a more family based assignment of class, particularly for women, for some of whom, access to social and economic resources are less defined by the labour market than they are for men.

\section{Calculating life expectancy}

Period life expectancy for a particular NS-SEC class is the average number of years a person would live, if he or she experienced the age-specific mortality rates for that time period, (for example 2002-06), for that class throughout his or her life. It makes no allowance for any future changes in age-specific mortality rates. Period life expectancies are a useful measure of mortality rates actually experienced in a given period and provide an objective means of comparison of the trends in mortality over time, between areas of a country and with other countries. Official life tables in the UK and in other countries which relate to past years are generally period life tables for these reasons. Cohort life expectancies, which attempt to project the actual number of years someone living now can expect to live, usually require projected mortality rates for their calculation and hence, in such cases, involve an element of judgement about future trends. 
Life tables are driven by age-specific mortality rates which were derived (for five-year age bands) using deaths and person years survived at risk for each NS-SEC class occurring in each five year period from 1982, calculated using Stata software. The tables, including variances and confidence intervals were derived using ONS standard methodology based on Chiang's method for deriving $q_{x}$, (the probability of death in each interval) and variances (Chiang, 1968).

While the LS does not suffer attrition in the way that many surveys do, it is well documented that there are 'losses to follow up' where existing sample members are not present at a census and yet have no record of death or embarkation. Methods for dealing with this problem were explored in depth in Johnson and Blackwell (2007), and analogous methods were used in this paper.

Sensitivity tests were carried out to measure the impact on the results of different approaches to excluding sample members who were possibly no longer at risk.

\section{Results}

Table 1 shows the prediction of reduced NS-SEC using the 1981 derivation matrix against those based on the 1991 matrix and SOC90 occupation codes for males and females under aged 75 in 1993. 


\section{Table 1 Cross-tabulation of death registrations in 1993 classified according to NS-SEC ${ }^{1}$ based on 1981 occupation (NS- SEC80) and 1991 occupation (NS-SEC90)}

England and Wales

1981 occupation (NS-SEC80) and 1991 occupation (NS-SEC90)

NS-SEC based on 1981 occupation

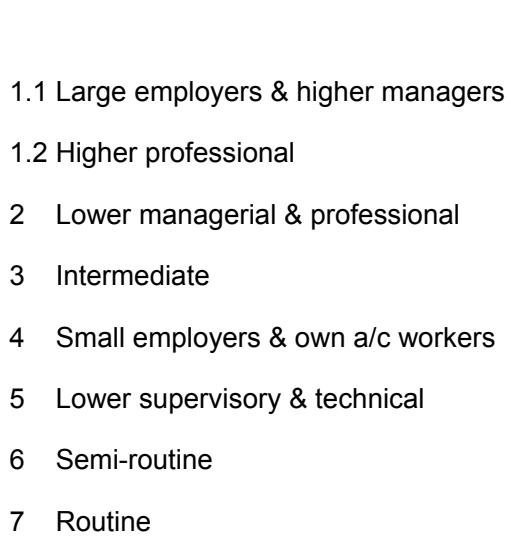

\begin{tabular}{rrrrrrrrr}
$\mathbf{7}$ & \multicolumn{2}{c}{ NS-SEC90 } & & & & & \\
$\mathbf{1 . 1}$ & $\mathbf{1 . 2}$ & $\mathbf{2}$ & $\mathbf{3}$ & $\mathbf{4}$ & $\mathbf{5}$ & $\mathbf{6}$ & $\mathbf{7}$ & \\
$\mathbf{4 , 8 2 3}$ & 20 & 50 & 0 & 0 & 0 & 0 & 0 & 4,893 \\
4 & 6143 & 38 & 33 & 0 & 0 & 0 & 0 & 6,218 \\
216 & 89 & 24,049 & 828 & 6 & 40 & 33 & 0 & 25,261 \\
0 & 11 & 40 & 20,771 & 0 & 0 & 50 & 36 & 20,908 \\
0 & 18 & 0 & 0 & 15,026 & 0 & 0 & 0 & 15,044 \\
0 & 0 & 0 & 0 & 0 & 22,701 & 113 & 242 & 23,056 \\
0 & 0 & 0 & 191 & 0 & 76 & 33,056 & 636 & 33,959 \\
0 & 0 & 0 & 0 & 0 & 16 & 187 & 46,615 & 46,818 \\
& & & & & & & &
\end{tabular}

1 Reduced derivation, children classified according to mother's occupation.

The proportion of the population in off-diagonal cells represents the 'error' in assignment when 1981 occupational information is used to derive NS-SEC, using the simple majority method for assigning NS-SEC to ambiguous cells. The percentage error measured in this way was 1.7 per cent.

A slightly greater error of 2.5 per cent was found when applying a similar method to the dual-coded LS 1991 Census occupation data - the constructed 1981 derivation matrix was used to predict NSSEC90 codes for sample members based on their occupation code. This scale of error is fairly small relative to the generally accepted levels of routine error in form completion and coding. However, since these errors are systematic rather than random, it is important that they are as small as possible.

The error was reduced to just under 1 per cent when industry codes were used to discriminate in cases where the NS-SEC class was ambiguous.

Tables $2 \mathrm{a}$ and $2 \mathrm{~b}$ show the main results of the study for males at birth and at age 65 respectively, using the conventional method for assignment of socio-economic class, (as used for the 'Trends in life expectancy by Social Class' series). The results are shown both for the seven analytic NS-SEC classes and for the condensed three-class schema. Class 1 (Higher managerial and professional) was split into its two components: 1.1 Large employers and higher managerial and 1.2 Higher professional occupations), since previous studies have found significant differences between the two subgroups. However, the confidence intervals for both classes 1.1 and 1.2 were relatively wide 
and so in estimating the range in life expectancy, from most to least advantaged, the whole of NSSEC class 1 was used in order to reduce the volatility from one period to the next resulting from sampling variance. The life expectancy of those unclassified by occupation is also shown. Owing to the potential change in composition of this group over time and selection effects, it was not used in estimating the range from most to least advantaged.

Figure 1 shows graphically life expectancy at birth by analytic class NS-SEC for men.

Table 3 shows the change in life expectancy for males for each analytical class over the whole study period and between the periods 1997-2001 to 2002-06 to aid comparison of classes over time.

Table 4 shows the corresponding estimates by social class for comparison with those by NS-SEC. These were previously published for the period 1972-2005 and are now updated to include 2006 in the latest reported period.

Tables $5 a$ and 5b, 6 and 7 and Figure 2 show the corresponding information for women. 


\section{Table 2a Life expectancy by NS-SEC class, males at birth}

England and Wales

Years

\begin{tabular}{lcccccc}
\hline & 1982-86 & 1987-91 & 1992-96 & 1997-2001 & 2002-06 \\
\hline NS-SEC & LE $95 \%$ & LE 95\% & LE $95 \%$ & LE & $95 \%$ & LE $95 \%$ \\
& $\mathrm{Cl}$ & $\mathrm{Cl}$ & $\mathrm{Cl}$ & $\mathrm{Cl}$ & $\mathrm{Cl}$ \\
& $(+/-)$ & $(+/-)$ & $(+/-)$ & $(+/-)$ & $(+/-)$
\end{tabular}

At birth

\section{Analytic classes}

1. Higher managerial \& professional
$\begin{aligned} & 1.1 \text { Large employers \& higher } \\ & \text { managers }\end{aligned}$
1.2 Higher professional
2 Lower managerial \& professional
3 Intermediate
4 Small employers \& own a/c workers
5 Lower supervisory \& technical
6 Semi-routine
7 Routine

Range highest- lowest

\section{Condensed NS-SEC}

Managerial \& professional

Intermediate

Routine \& manual

Range highest- lowest

Unclassified

$\begin{array}{llllllllll}75.6 & 0.7 & 76.6 & 0.6 & 77.5 & 0.6 & 78.8 & 0.7 & 80.4 & 0.6 \\ 75.1 & 1.1 & 75.6 & 1.0 & 77.0 & 1.0 & 79.0 & 1.0 & 79.9 & 0.9 \\ 76.5 & 1.1 & 77.7 & 0.9 & 78.0 & 0.9 & 78.5 & 0.9 & 80.6 & 0.8 \\ 74.3 & 0.7 & 75.4 & 0.6 & 76.5 & 0.6 & 78.2 & 0.5 & 79.6 & 0.5 \\ 73.3 & 0.8 & 74.5 & 0.8 & 75.3 & 0.8 & 76.8 & 0.8 & 78.5 & 0.8 \\ 73.6 & 0.8 & 74.4 & 0.8 & 75.6 & 0.7 & 76.6 & 0.7 & 77.8 & 0.7 \\ 72.3 & 0.6 & 73.2 & 0.6 & 73.8 & 0.6 & 75.3 & 0.6 & 76.8 & 0.6 \\ 71.3 & 0.6 & 71.7 & 0.6 & 72.4 & 0.6 & 74.0 & 0.6 & 75.1 & 0.6 \\ 70.7 & 0.5 & 71.5 & 0.5 & 71.6 & 0.5 & 72.6 & 0.5 & 74.6 & 0.5\end{array}$

4.9

5.1

5.9

6.2

5.8

$\begin{array}{ll}74.8 & 0.5 \\ 73.5 & 0.5 \\ 71.4 & 0.3\end{array}$

3.4

$60.2 \quad 1.4$

$60.3 \quad 1.2$

$65.8 \quad 1.3$

$67.2 \quad 1.2$

$71.5 \quad 1.1$

$\begin{array}{llll}72.6 & 0.2 & 73.8 & 0.2\end{array}$

\begin{tabular}{llll}
75.2 & 0.2 & 77.0 & 0.2 \\
\hline
\end{tabular}

Source: ONS Longitudinal Study 
However, higher professionals, (class 1.2) appeared to have a higher life expectancy than large employers and higher managers (class 1.1) in most periods. Differences between the two classes were not statistically significant for periods from 1992 onwards.

Only the differences between NS-SEC class 4, the self-employed and own account occupations, and class 5 (lower supervisory and technical occupations), and between class 5 and class 6 (semiroutine) were statistically significant in every period, but the pattern of the gradient through time suggests that it is a persistent phenomenon. The largest gap between any two adjacent analytical classes in 2002-06 was between lower supervisory and technical occupations and semi-routine occupations (1.7 years). The range in years between the classes with the highest and the lowest life expectancies at birth widened over time from 4.9 years in 1982-86 to 6.2 years in 1997-2001. The gap narrowed to 5.8 years in 2002-06 but this was not a statistically significant change.

The pattern of the range over time was similar for the 3-class condensed version of NS-SEC, but this did not exhibit narrowing in the latest period. The reason for the difference was that the least advantaged of the analytic classes (Routine occupations) was responsible for a high proportion of the increase in the life expectancy of the 'labour contract' group. Table 3 shows that the Routine occupations class had the second highest increase in life expectancy of any class between the periods 1997-2001 and 2002-06, while the Lower supervisory and technical class and semiroutine occupations class had only average increases. Table 3 also shows that, over the whole study period, the Routine class had the second lowest increase over the whole period and the Routine and manual grouping had the lowest aggregate increase of the condensed NS-SEC classes. 


\section{Table 3 Change in life expectancy at birth and at age 65 by NS-SEC, males}

England and Wales

Years

NS-SEC

At birth

Analytic classes

1. Higher managerial \& professional

1.1 Large employers \& higher managers

1.2 Higher professional

2 Lower managerial \& professional

3 Intermediate

4 Small employers \& own a/c workers

5 Lower supervisory \& technical

6 Semi-routine

7 Routine

\section{Condensed NS-SEC}

Managerial \& professional

Intermediate

Routine \& manual

Unclassified

All Men Change between 1982-86 and Change between $1997-01$ and
2002-06 2002-06

$\begin{array}{ll}4.8 & 1.6 \\ 4.8 & 0.9 \\ 4.1 & 2.1 \\ 5.3 & 1.4 \\ 5.2 & 1.7 \\ 4.2 & 1.2 \\ 4.5 & 1.5 \\ 3.8 & 1.1 \\ 3.9 & 2.0\end{array}$

5.2

1.6

4.6

1.4

4.0

1.7

11.3

4.3

5.3

\section{At age 65}

\section{Analytic classes}

1. Higher managerial \& professional

1.1 Large employers \& higher managers

0.7

1.2 Higher professional

0.6

2 Lower managerial \& professional

3 Intermediate

4 Small employers \& own a/c workers

5 Lower supervisory \& technical

6 Semi-routine

7 Routine

\section{Condensed NS-SEC}

Managerial \& professional

Intermediate

Routine \& manual

Unclassified

3.1 
Figure 1 illustrates this pattern. The Intermediate and the self-employed, and own account occupations had the closest path over time. There appear to be clear gaps between occupations with the three major types of employment contract. There was also a persistent gap of between 1.5 and 2 years between Class 5 (Lower supervisory and technical) and Class 6 (Semi-routine).

Table $2 \mathrm{~b}$ suggests that a similar pattern across the classes was observed age 65 as at birth. The gap widened from 2.3 years in 1982-86 to 4.1 years in 1997-2001 and then narrowed to 3.5 years in 2002-06.

Those unclassified by occupation had consistently lower life expectancy than the analytic classes.

\section{Figure 1 Life expectancy by NS-SEC class, males at birth}

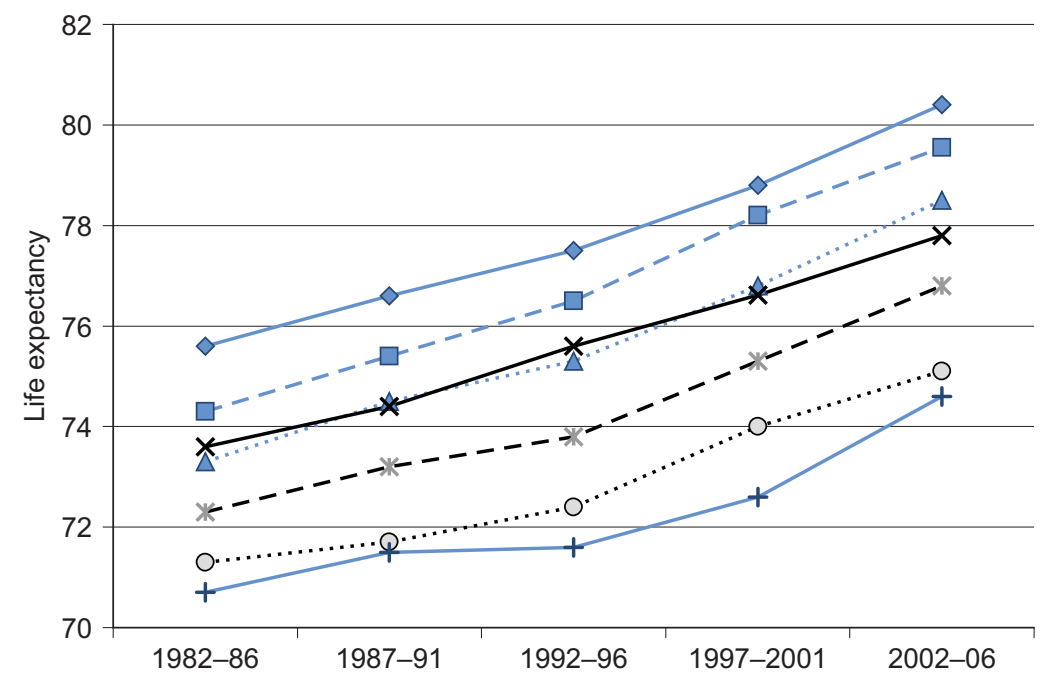

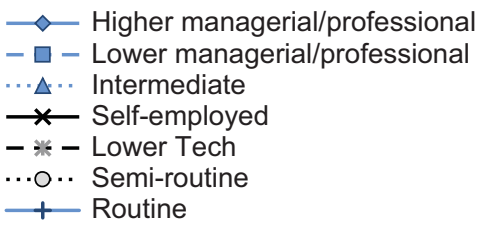

Source: ONS Longitudinal Study 


\section{Table $4 \quad$ Life Expectancy at birth and at age 65 by social class, males}

England and Wales

Years

\begin{tabular}{|c|c|c|c|c|c|c|c|c|c|c|c|c|c|c|}
\hline \multirow[b]{2}{*}{ Social Class } & \multicolumn{2}{|c|}{$1972-76$} & \multicolumn{2}{|c|}{$1977-81$} & \multicolumn{2}{|c|}{$1982-86$} & \multicolumn{2}{|c|}{ 1987-91 } & \multicolumn{2}{|c|}{ 1992-96 } & \multicolumn{2}{|c|}{$1997-2001$} & \multicolumn{2}{|c|}{$2002-06$} \\
\hline & LE & $\begin{array}{c}95 \% \\
\mathrm{Cl} \\
(+/-)\end{array}$ & & $\begin{array}{c}95 \% \\
\mathrm{Cl} \\
(+/-)\end{array}$ & LE & $\begin{array}{c}95 \% \\
\mathrm{Cl} \\
(+/-)\end{array}$ & LE & $\begin{array}{c}95 \% \\
\mathrm{Cl} \\
(+/-)\end{array}$ & LE & $\begin{array}{c}95 \% \\
\mathrm{Cl} \\
(+/-)\end{array}$ & LE & $\begin{array}{c}95 \% \\
\mathrm{Cl} \\
(+/-)\end{array}$ & LE & $\begin{array}{c}95 \\
\% \\
\mathrm{Cl} \\
(+/-)\end{array}$ \\
\hline
\end{tabular}

At birth

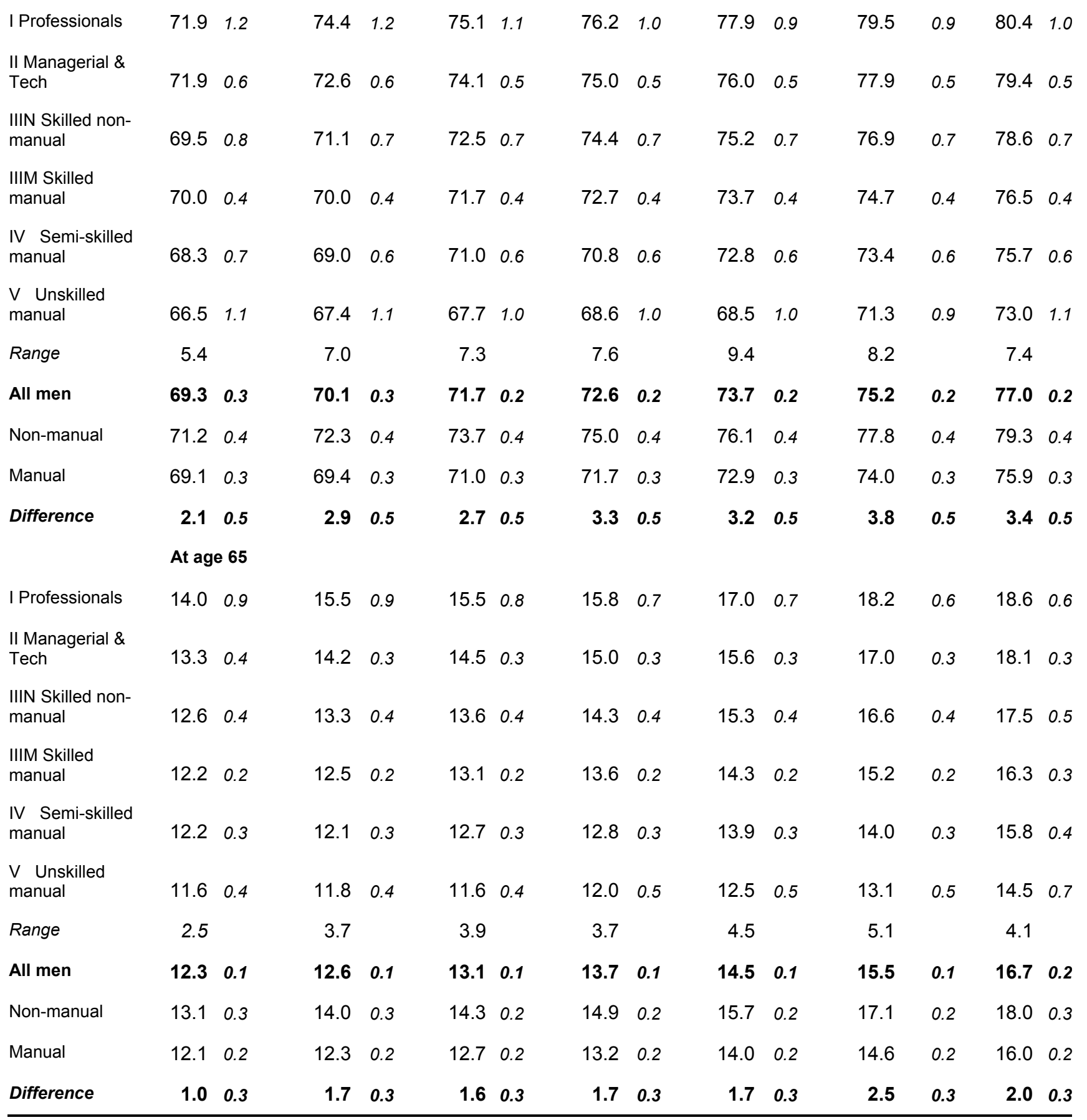

Source: ONS Longitudinal Study 
Comparison with Table 4 showing life expectancy by social class for males, shows that the ranges are similar for both NS-SEC and RG social class. The range between the most and least advantaged classes is not as great for NS-SEC as for social class, (5.8 years in 2002-06 for NSSEC compared with 7.4 years for social class). The main reason is that Social Class $V$, 'unskilled manual occupations', is a smaller class than 'Routine occupations' in the NS-SEC schema. In both cases there is a narrowing of the range in the most recent period. This narrowing was statistically significant for social class at age 65 . At birth the widest gap between social classes I and $\mathrm{V}$ was in 1992-96, rather than 1997-2001. This was almost certainly a result of the small size and consequently wide confidence interval (in excess of one year) for social class $\mathrm{V}$.

Table 5a shows that there was also a persistent socio-economic gradient for females. As for men, higher professionals tended to have a higher life expectancy than higher managers, although the difference between these classes was only statistically significant for the most recent period. The range between the highest and lowest life expectancy was smaller than for men (4.2 years at birth and 3.2 years at age 65, compared with 5.8 years and 3.5 years for men in the period 2002-06). 


\section{Table 5a Life expectancy by NS-SEC class, females at birth}

England and Wales

Years

\begin{tabular}{|c|c|c|c|c|c|c|c|c|c|c|}
\hline \multirow[b]{2}{*}{ NS-SEC } & \multicolumn{2}{|c|}{$1982-86$} & \multicolumn{2}{|c|}{ 1987-91 } & \multicolumn{2}{|c|}{ 1992-96 } & \multicolumn{2}{|c|}{ 1997-2001 } & \multicolumn{2}{|c|}{ 2002-06 } \\
\hline & LE & $\begin{array}{c}95 \% \\
\mathrm{Cl} \\
(+/-)\end{array}$ & LE & $\begin{array}{c}95 \% \\
\mathrm{Cl} \\
(+/-)\end{array}$ & LE & $\begin{array}{c}95 \% \\
\mathrm{Cl} \\
(+/-)\end{array}$ & LE & $\begin{array}{c}95 \% \\
\mathrm{Cl} \\
(+/-)\end{array}$ & LE & $\begin{array}{c}95 \% \\
\mathrm{Cl} \\
(+/-)\end{array}$ \\
\hline
\end{tabular}

At birth

Analytic classes

1. Higher managerial \& professional

80.91

$81.7 \quad 1.0$

$82.3 \quad 0.9$

$82.6 \quad 0.8$

$83.9 \quad 0.7$

1.1 Large employers \& higher managers

$\begin{array}{ll}79.9 & 1.7\end{array}$

$82.3 \quad 1.5$

$82.1 \quad 1.5$

$81.5 \quad 1.3$

$82.7 \quad 1.3$

$81.9 \quad 1.2$

$83.0 \quad 1.1$

1.2 Higher professional

\section{$\begin{array}{ll}79.7 & 0.7\end{array}$}

$81.0 \quad 0.6$ professional

$\begin{array}{ll}79.6 & 0.7\end{array}$

$81.1 \quad 0.7$

$82.0 \quad 1.3$

83.01 .1

$84.8 \quad 1.0$

3 Intermediate

4 Small employers \& own a/c workers

$79.1 \quad 1.0$

$\begin{array}{ll}79.9 & 0.9\end{array}$

$\begin{array}{ll}78.5 & 0.9\end{array}$

\begin{tabular}{ll}
$78.1 \quad 0.8$ \\
\hline
\end{tabular}

$78.1 \quad 0.6$

$78.5 \quad 0.6$

$77.1 \quad 0.6$

$\begin{array}{ll}77.5 & 0.6\end{array}$

$81.2 \quad 0.5$

82.20 .5

$83.4 \quad 0.5$

6 Semi-routine

7 Routine

Range highest- lowest

3.8

4.2

4.0

4.0

4.2

\section{Condensed NS-SEC}

Managerial \& professional
Intermediate
Routine \& manual

Range highest- lowest

Unclassified

$71.5 \quad 1.1$

$73.1 \quad 1.0$

$74.2 \quad 1.2$

$75.8 \quad 0.9$

$\begin{array}{ll}76.9 & 0.9\end{array}$

All Women

$\begin{array}{ll}77.4 & 0.2\end{array}$

$\begin{array}{ll}78.3 & 0.2\end{array}$

$\begin{array}{ll}79.2 & 0.2\end{array}$

$\begin{array}{ll}79.9 & 0.2\end{array}$

$81.1 \quad 0.2$ 


\section{Table 5b Life expectancy by NS-SEC class, females at age 65}

England and Wales

Years

\begin{tabular}{|c|c|c|c|c|c|c|c|c|c|}
\hline \multirow[b]{2}{*}{ NS-SEC } & \multicolumn{2}{|c|}{ 1982-86 } & \multicolumn{2}{|c|}{$1987-91$} & \multicolumn{2}{|c|}{$1992-96$} & \multicolumn{2}{|c|}{ 1997-2001 } & 2002-06 \\
\hline & LE & $\begin{array}{c}95 \% \\
\mathrm{Cl} \\
(+/-)\end{array}$ & LE & $\begin{array}{c}95 \% \\
\mathrm{Cl} \\
(+/-)\end{array}$ & LE & $\begin{array}{c}95 \% \\
\mathrm{Cl} \\
(+/-)\end{array}$ & LE & $\begin{array}{c}95 \% \\
\mathrm{Cl} \\
(+/-)\end{array}$ & $\begin{array}{c}\text { LE } 95 \% \\
\mathrm{Cl} \\
(+/-)\end{array}$ \\
\hline
\end{tabular}

\section{At age 65}

\section{Analytic classes}

\begin{tabular}{|c|c|}
\hline & Higher managerial \& professional \\
\hline & $\begin{array}{l}1.1 \text { Large employers \& higher } \\
\text { managers }\end{array}$ \\
\hline & 1.2 Higher professional \\
\hline 2 & Lower managerial \& professional \\
\hline 3 & Intermediate \\
\hline 4 & $\begin{array}{l}\text { Small employers \& own a/c } \\
\text { workers }\end{array}$ \\
\hline 5 & Lower supervisory \& technical \\
\hline & Semi-routine \\
\hline & Routine \\
\hline
\end{tabular}

Range highest- lowest

\section{Condensed NS-SEC}

Managerial \& professional

Intermediate

Routine \& manual

Range highest- lowest

Unclassified

All Women
$19.7 \quad 1.0$

$19.4 \quad 1.5$

$20.0 \quad 1.3$

$18.9 \quad 0.6$

$18.3 \quad 0.6$

$\begin{array}{ll}18.6 & 0.8\end{array}$

$\begin{array}{ll}18.7 & 0.7\end{array}$

$\begin{array}{ll}17.4 & 0.5\end{array}$

$\begin{array}{ll}16.7 & 0.4\end{array}$

3.0

2.7

$20.6 \quad 1.4$

$19.8 \quad 1.0$

$19.4 \quad 0.5$

$19.5 \quad 0.5$

$\begin{array}{ll}18.9 & 0.7\end{array}$

$\begin{array}{ll}17.6 & 0.5\end{array}$

$17.6 \quad 0.4$

$17.4 \quad 0.4$

3.1

$19.6 \quad 0.6$

$18.3 \quad 0.5$

$18.3 \quad 0.4$

$\begin{array}{ll}17.7 & 0.3\end{array}$

3.1

19.10 .6

$18.3 \quad 0.5$

$18.4 \quad 0.3$

$\begin{array}{ll}17.8 & 0.3\end{array}$

0.3

$18.5 \quad 0.3$

$\begin{array}{llll}19.1 & 0.5 & 19.6 & 0.4 \\ 18.4 & 0.5 & 19.3 & 0.4 \\ 17.3 & 0.3 & 17.5 & 0.2\end{array}$

2.1

$16.2 \quad 0.3$

$16.2 \quad 0.2$

$\begin{array}{ll}17.0 & 0.1\end{array}$

$\begin{array}{ll}17.5 & 0.1\end{array}$

$\begin{array}{ll}18.0 & 0.1\end{array}$

$18.5 \quad 0.1$

$\begin{array}{ll}21.3 & 0.3\end{array}$

$20.5 \quad 0.3$

$18.9 \quad 0.2$

$18.0 \quad 0.2$

$\begin{array}{ll}18.1 & 0.2\end{array}$

2.3

$16.3 \quad 0.3$

$16.6 \quad 0.4$

$17.4 \quad 0.5$

Source: ONS Longitudinal Study 
The range did not show the same pattern as for men, with no identifiable trend and no sign of a narrowing between the most and least advantaged. The greatest relative change among classes appeared to be the growth of the life expectancy of Classes 2 (Lower professional) and 4 (Selfemployed and own-account occupations). The latter class closed the gap between it and the intermediate class from 1.2 years in 1987-91 to a negligible 0.1 years in 2002-06. As for men, there was a clear difference between the 'labour contract' group, (the least advantaged), and the intermediate group, but in the case of women, this difference was greater as a proportion of the overall range across the classes. Table 6 suggests that the three labour contract analytic classes were those with the least increase in life expectancy over the study period. 


\section{Table 6 Change in life expectancy at birth and at age 65 by NS-SEC, females}

NS-SEC

\begin{tabular}{|c|c|c|}
\hline 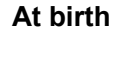 & $\begin{array}{l}\text { Change between } 1982-86 \text { and } \\
\text { 2002-06 }\end{array}$ & $\begin{array}{l}\text { Change between 1997- } \\
2001 \text { and 2002-06 }\end{array}$ \\
\hline
\end{tabular}

\section{Analytic classes}

1. Higher managerial \& professional

1.1 Large employers \& higher managers

1.2 Higher professional

2 Lower managerial \& professional

3 Intermediate

4 Small employers \& own a/c workers

5 Lower supervisory \& technical

6 Semi-routine

7 Routine

\section{Condensed NS-SEC}

Managerial \& professional

Intermediate 3.1

Routine \& manual

Unclassified 5.4

All Women

\section{8 analytic classes}

1. Higher managerial \& professional

1.1 Large employers \& higher managers

2 Lower managerial \& professional

3 Intermediate

4 Small employers \& own a/c workers

5 Lower supervisory \& technical

6 Semi-routine

7 Routine

\section{Condensed NS-SEC}

Managerial \& professional

Intermediate 2.1 
Figure 2 illustrates the relative increase in the life expectancy of the self-employed and own account workers and the persistent gap between the labour contract occupations and the rest.

\section{Figure 2 Life expectancy by NS-SEC class, females at birth}

\section{England and Wales \\ Years}

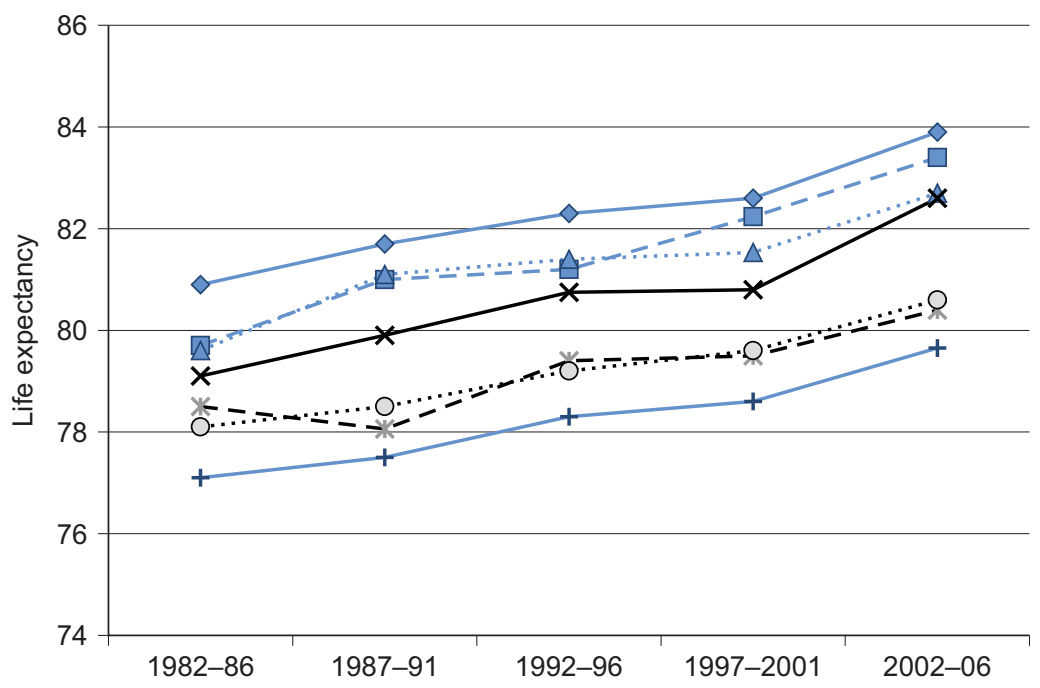

$\checkmark$ Higher managerial/professional $-\square-$ Lower managerial/professional $\cdots \triangle \cdots$ Intermediate

$\rightarrow$ - Self-employed

- * - Lower Tech

... o.... Semi-routine

+ Routine

Source: ONS Longitudinal Study 


\section{Table $7 \quad$ Life Expectancy at birth and at age 65 by social class, females}

\begin{tabular}{|c|c|c|c|c|c|c|c|c|c|c|c|c|c|c|}
\hline \multirow[t]{2}{*}{ England and Wales } & & & & & & & & & & & & & Years & \\
\hline & \multicolumn{2}{|c|}{$1972-76$} & \multicolumn{2}{|c|}{$1977-81$} & \multicolumn{2}{|c|}{$1982-86$} & \multicolumn{2}{|c|}{ 1987-91 } & \multicolumn{2}{|c|}{ 1992-96 } & \multicolumn{2}{|c|}{ 1997-2001 } & \multicolumn{2}{|c|}{ 2002-06 } \\
\hline \multirow[t]{2}{*}{ Social Class } & LE & $\begin{array}{c}95 \% \\
\mathrm{Cl} \\
(+/-)\end{array}$ & LE & $\begin{array}{c}95 \% \\
\mathrm{Cl} \\
(+/-)\end{array}$ & LE & $\begin{array}{c}95 \% \\
\mathrm{Cl} \\
(+/-)\end{array}$ & LE & $\begin{array}{c}95 \% \\
\mathrm{Cl} \\
(+/-)\end{array}$ & LE & $\begin{array}{c}95 \% \\
\mathrm{Cl} \\
(+/-)\end{array}$ & LE & $\begin{array}{c}95 \% \\
\mathrm{Cl} \\
(+/-)\end{array}$ & LE 9 & $\begin{array}{c}95 \% \\
\mathrm{Cl} \\
(+/-)\end{array}$ \\
\hline & \multicolumn{14}{|c|}{ At birth } \\
\hline I Professionals & 79.0 & 1.9 & 80.1 & 1.7 & 80.7 & 1.3 & 81.1 & 1.1 & 83.8 & 1.1 & 82.5 & 1.0 & 85.2 & 1.1 \\
\hline $\begin{array}{l}\text { II Managerial \& } \\
\text { tech }\end{array}$ & 77.1 & 0.6 & 78.3 & 0.6 & 78.8 & 0.5 & 80.7 & 0.5 & 81.3 & 0.5 & 81.7 & 0.5 & 83.1 & 0.5 \\
\hline $\begin{array}{l}\text { IIIN Skilled non- } \\
\text { manual }\end{array}$ & 78.3 & 0.7 & 78.2 & 0.7 & 79.0 & 0.6 & 80.0 & 0.5 & 80.7 & 0.5 & 81.6 & 0.5 & 82.5 & 0.5 \\
\hline IIIM Skilled manual & 75.2 & 0.6 & 76.3 & 0.5 & 77.3 & 0.5 & 77.9 & 0.5 & 79.1 & 0.4 & 79.4 & 0.4 & 80.6 & 0.5 \\
\hline $\begin{array}{l}\text { IV Semi-skilled } \\
\text { manual }\end{array}$ & 75.3 & 0.7 & 75.9 & 0.6 & 77.5 & 0.6 & 77.4 & 0.5 & 78.1 & 0.5 & 78.7 & 0.5 & 79.9 & 0.6 \\
\hline $\begin{array}{l}\mathrm{V} \text { Unskilled } \\
\text { manual }\end{array}$ & 74.2 & 1.2 & 75.6 & 1.0 & 75.9 & 0.9 & 76.6 & 0.9 & 77.4 & 0.9 & 77.8 & 0.9 & 78.3 & 1.2 \\
\hline Range & 4.8 & & 4.4 & & 4.8 & & 4.5 & & 6.4 & & 4.7 & & 6.9 & \\
\hline All women & 75.3 & 0.3 & 76.5 & 0.2 & 77.4 & 0.2 & 78.3 & 0.2 & 79.1 & 0.2 & 79.9 & 0.2 & 81.1 & 0.2 \\
\hline Non-manual & 77.7 & 0.4 & 78.4 & 0.4 & 79.0 & 0.4 & 80.4 & 0.3 & 81.2 & 0.3 & 81.7 & 0.3 & 82.9 & 0.3 \\
\hline Manual & 75.2 & 0.4 & 76.0 & 0.4 & 77.2 & 0.3 & 77.5 & 0.3 & 78.4 & 0.3 & 78.9 & 0.3 & 80.0 & 0.3 \\
\hline Difference & 2.5 & 0.6 & 2.4 & 0.5 & 1.9 & 0.5 & 2.9 & 0.5 & 2.8 & 0.4 & 2.8 & 0.4 & 2.9 & 0.5 \\
\hline
\end{tabular}

\section{At age 65}

\begin{tabular}{|c|c|c|c|c|c|c|c|c|c|c|c|c|c|c|}
\hline I Professionals & 19.1 & 1.7 & 20.0 & 1.5 & 18.9 & 1.1 & 19.0 & 0.8 & 21.1 & 0.9 & 20.7 & 0.8 & 22.0 & 0.9 \\
\hline $\begin{array}{l}\text { II Managerial \& } \\
\text { tech }\end{array}$ & 17.2 & 0.4 & 17.8 & 0.4 & 18.2 & 0.4 & 19.2 & 0.3 & 19.7 & 0.3 & 20.0 & 0.3 & 21.0 & 0.3 \\
\hline $\begin{array}{l}\text { IIIN Skilled non- } \\
\text { manual }\end{array}$ & 17.9 & 0.6 & 17.7 & 0.4 & 18.2 & 0.4 & 18.7 & 0.3 & 19.2 & 0.3 & 19.8 & 0.3 & 20.1 & 0.3 \\
\hline IIIM Skilled manual & 16.4 & 0.5 & 16.9 & 0.4 & 16.9 & 0.3 & 17.2 & 0.3 & 18.1 & 0.3 & 18.2 & 0.3 & 18.8 & 0.4 \\
\hline $\begin{array}{l}\text { IV Semi-skilled } \\
\text { manual }\end{array}$ & 16.9 & 0.4 & 16.8 & 0.3 & 17.5 & 0.3 & 17.3 & 0.3 & 17.4 & 0.3 & 17.9 & 0.3 & 19.0 & 0.3 \\
\hline $\begin{array}{l}\mathrm{V} \text { Unskilled } \\
\text { manual }\end{array}$ & 16.6 & 0.7 & 16.4 & 0.6 & 16.2 & 0.5 & 16.3 & 0.5 & 16.6 & 0.5 & 16.8 & 0.5 & 17.7 & 0.6 \\
\hline Range & 2.5 & & 3.6 & & 2.7 & & 2.7 & & 4.5 & & 3.9 & & 4.2 & \\
\hline All women & 16.3 & 0.1 & 16.7 & 0.1 & 17.0 & 0.1 & 17.5 & 0.1 & 18.0 & 0.1 & 18.5 & 0.1 & 19.5 & 0.2 \\
\hline Non-manual & 17.5 & 0.3 & 17.9 & 0.3 & 18.2 & 0.2 & 18.9 & 0.2 & 19.5 & 0.2 & 19.9 & 0.2 & 20.6 & 0.2 \\
\hline Manual & 16.6 & 0.3 & 16.8 & 0.2 & 17.0 & 0.2 & 17.1 & 0.2 & 17.5 & 0.2 & 17.8 & 0.2 & 18.7 & 0.2 \\
\hline Difference & 0.9 & 0.4 & 1.1 & 0.4 & 1.2 & 0.3 & 1.8 & 0.3 & 2.0 & 0.3 & 2.1 & 0.3 & 1.9 & 0.3 \\
\hline
\end{tabular}

Source: ONS Longitudinal Study 
In comparison with the results by social class, shown in Table 7, the range between the most and least advantaged was smaller and more stable for NS-SEC than for social class, again possibly because of the small size and greater variation in social class V. Condensed NS-SEC showed a similar range and pattern to the non-manual/manual divide by social class at birth, although the pattern at age 65 was slightly different.

The results of using a 'combined' measure of classification of spouses or fathers and mothers of children are shown in Tables A1 and A2 of the Appendix. The main effect of using the combined measure of NS-SEC was to widen the gap slightly between the most and the least advantaged, both for men and for women. In 2002-06 this widening was 0.2 years for males at birth and 1.1 years for females. This was a result of the decrease in the life expectancy estimates of the Routine class under the 'combined' rule in both cases. The narrowing of the range between highest and lowest in the most recent period was more pronounced for men under the combined classification, reducing from 6.8 years to 6.0 . For men at age 65 , the reduction in the gap in the most recent period was from 4.4 years to 3.8 years.

For women, the effect was to accentuate the apparent increase in range in the most recent period Otherwise, the effect on the estimates of the combined classification was small.

\section{Discussion}

These results continue the pattern shown in previously published estimates of trends in life expectancy by RG social class. There was a clear social gradient in the life expectancy estimates for both males and females, which persisted through the period 1982-86 to 2002-06. The overall range between the most advantaged (higher managers or higher professionals), and the least advantaged (Routine occupations), was slightly less than the range across the occupied RG social classes for 2002-06, (around six years compared with over seven years for RG social class for males at birth). The range appeared to increase in the 1990s and, for males, to narrow slightly in the early part of the 21st Century. The range in life expectancy at birth between NS-SEC class 1 (Higher managerial and professional occupations) and class 7 (Routine occupations) fell from 6.2 years in 1997-2001 to 5.8 years in 2002-06, and from 4.1 years to 3.5 years at age 65 . While this only represents a return to the inequality of the 1990s, it does appear to be a change from the earlier trend between 1982-86 and 1997-2001. It is dangerous to attach too much significance to the figures of a single period, but these results are consistent with the hypothesis that inequalities were no longer rising for males in the early 2000s, as they had done up to 1997-2001. It would be necessary to observe another period with a substantial relative improvement in life expectancy for the Routine class before there could be confidence that a turning point had been reached for inequalities in male mortality. The relative improvement in the Routine class for men was consistent with the findings of Langford and Johnson (2010), using a cross-sectional method with the Labour Force Survey forming the basis for population denominators. This suggested that mortality rates at working age for Routine class males fell by the most of any of the NS-SEC analytic classes between 2001 and 2008.

No corresponding pattern was visible for females, for whom those assigned to Routine and manual occupations seemed to continue to decline in relative life expectancy. 
Lower managerial and professional occupations was the class with the greatest increase in life expectancy at birth over the study period for both males (5.3 years) and females (3.7 years). The Semi-routine class had the lowest increase for men (3.8 years) and the Lower supervisory and technical class had the lowest increase for women (1.9 years).

Those not classified by NS-SEC had a lower expectation of life than those who could be assigned a class based occupation. This group includes full-time students; the long-term unemployed; those who never worked; and those whose occupation was inadequately described or were unclassified for other reasons. Since the method used should be capable of classifying those who were unemployed for a short time or recently retired, and since spouse's class was used if the sample member could not be classified, and father or mother's class was used for children, a high proportion of those who remain unclassified could be thought to be composed of the least advantaged in society, since there is no link to the labour market apparent from available sources.

It is not surprising, therefore, that the unclassified group had low life expectancy estimates. However there is almost certainly a selection effect operating. Unclassified men had a life expectancy of 60.2 years in 1982-86. There was a negligible increase to 60.3 in 1987-91, but then the life expectancy jumped to 65.8 in 1992-96. Fox et al. (1985) showed that in the period from 5 to 10 years post-classification, the manual social classes had substantially higher mortality and the unoccupied lower mortality compared with the period immediately post-classification. In the current study, selection seemed to have a longer lasting effect, whereby it appeared to take at least 10 years for the effect of those with incipient ill health to wear off via their death or recovery. Changes in the relative life expectancy of the unclassified may also be partly explained by changes in the composition of the group over time. However, the trend over time in the life expectancy of the unclassified is not adequately explained and further analysis is necessary.

\section{Differences within NS-SEC class 1}

A slightly unexpected result was the higher life expectancy for higher professionals (NS-SEC class 1.2) than for higher managers (class 1.1). Cross-sectional studies using the 2001 Census and death registrations have usually found lower mortality (at working age) for class 1.1. A test of the impact of each occupation which was mainly classified to classes 1.1 and 1.2 did not suggest that any one occupation had a disproportionate effect on the relative life expectancies of the two groups. Fitzpatrick (2003) found that use of reduced NS-SEC had a substantial effect on the size and composition of class 1.1. As a result, size of establishment was included as a variable where available, as a sensitivity test for the current study to approximate full NS-SEC and substituted for the reduced NS-SEC used to produce the life expectancy estimates. However the greater life expectancy of higher professionals relative to managers persisted irrespective of the inclusion of establishment size and industry data.

The confidence intervals around the estimates for Classes 1.1 and 1.2 were relatively wide at (or greater than) a year, and this can produce volatility in the ranking of the estimates. The persistence of the phenomenon makes it more likely that it is an artefact of the classification system used in 1991 and hence 1981 rather than a real reversal of the survival probabilities of managers and professionals between 1981 and the 21st Century. It should also be remembered that with the Registrar General's social class schema, class I was 'Professionals' and class II was 'managerial', (and subsequent to 1991 'managerial and technical' (OPCS, 1991)), and historically, class I tended to have higher life expectancy than class II. 


\section{Assignment of class}

The combined approach to classification was based on the concept of 'dominance' in the labour market, as proposed by Erikson (1984). The main effect of using the 'combined' measure of NSSEC was to widen the gap slightly between the most and least advantaged both for men and women. This increase in gradient was observed in the analysis of mortality rates of women of working age using a 'combined' measure in relation to using women's own NS-SEC (Langford and Johnson, 2009). All measures which attempt to include members of the household other than the sample member tend to have the effect of selecting from the more disadvantaged classes, those who are at the most socio-economic disadvantage, and often those who live alone. This tends to increase the average mortality rates of the least advantaged group. Nevertheless, estimates for most classes were not significantly different using the combined method for either males or females.

This contrasts with the cross-sectional analysis of female mortality at working ages for 2001-03 (Langford and Johnson, 2009), where applying such a combined approach tended to steepen the gradient substantially for all causes of death. This is not surprising since, in the latter case, the method allowed women to be classified by occupation at death where otherwise they would not have been. In the current study, the combined method did not bring people into analytic NS-SEC categories who would have otherwise remained unclassified, but simply reordered the hierarchy of rules by which a class was assigned.

Other methods of assignment to an NS-SEC class were considered. It has been suggested that classifying someone by their occupation-based class at, for example, age 22 might not adequately express a person's access to resources. In addition to a natural trajectory that occurs in some careers, there is a degree of social mobility which is not accounted for when classifying people at entry to the study. Donkin et al. (2002) attempted to classify sample members at later censuses. They found that for those classified in 1991 (the most recent census at the time) a high proportion could not be assigned a class since the census coded occupational information only for those under 75 years old. This, when combined with the clear evidence of health selection - 'life expectancy immediately following classification appears to be enhanced for those in social class V' (the least advantaged), tends to militate against constantly updating classifications in longitudinal studies of this type. The Black report (1980, p 358) suggested that ...childhood illness 'cast long shadows forward'. Power et al. (2005) indicated the link between socio-economic position in childhood and early life and the risk of mortality. Blane et al. (1999) observed that the upwardly mobile tend to have higher mortality and the downward mobile tend to have lower mortality than the average for their destination classes. White et al. (2005) found that social class in 1971 continued to have a strong influence on mortality risk in 1995-2001, after controlling for interim social mobility and unemployment, level of neighbourhood deprivation, and other factors. However, these authors acknowledge that it is an accumulation of disadvantage through the lifecourse which perpetuates these inequalities and that social mobility plays some role in health outcomes.

One compromise might be to update the classification for all those present at a census and capable of being assigned an occupation based socio-economic class, while retaining the existing class for those who are unclassified at the latest census. This would not completely eradicate any selection bias in that someone might have changed to a less demanding occupation owing to poor 
health, but it would not exacerbate the main problem - that arising from the effect of those selected out of the workforce altogether for health reasons.

\section{Use of occupation-based measures}

All methods of assigning socio-economic position based on occupation are subject to the weakness of occupation in describing access to material and social resources. NS-SEC has provided a conceptual basis for an occupation-based system whereby an explanation can be made of differences in mortality and survival, based on job stress, type of employment contract and other job-related factors, but is not designed to evaluate the role of social capital and other nonoccupation based factors, especially for women.

There is the additional problem that occupational structures are always changing. The current study required a construct of NS-SEC for 1981 occupations for which it was not designed. The empirical validity of this has been discussed in this article. While there is also a conceptual problem, it must be remembered that social class - while giving the appearance of continuity - had to change over time, owing to the existence of new occupations, the deskilling of others and various other structural changes. It was found that approximately 14 per cent of the 1971 Census cohort of men between ages 45 and 64 would have been assigned a different social class by the 1981 Census without any change of occupation (Goldblatt and Whitehead, 2000). Thus, any occupation-based measure is mutable in some way.

Educational attainment might be a better all round measure of 'social capital', and studies in Europe in particular have made use of these measures (Mackenbach et al., 2008, Corsini, 2010). However, these too have shortcomings, with types of qualification and the prevalence of qualifications changing over time. There is also a practical problem in England and Wales, with very limited educational attainment data being available from the 1981 and 1991 Censuses.

\section{Future developments}

The occupational classification system has recently been revised in time for the 2011 Census. It is not feasible to set out the impact of these changes here, but the main effects will be to reduce the number of occupations which qualify as 'managerial', and to increase the number of lower professionals. It is reasonable to assume that some further degree of discontinuity will result. However, this was always the case with Registrar General's social class and as NS-SEC becomes more recognised and understood, comparisons over time will become less problematic.

\section{Limitations of the analysis}

All occupation-based classifications change over time with changes in technology and economic structures. NS-SEC is no exception to this. Donkin et al. (2002) found only 84 per cent agreement at the analytic class level used in this study between NS-SEC90 and NS-SEC2001, when applied to dual coded 2001 first quarter deaths. Of the 16 per cent discrepancy, approximately 9 per cent was a result of occupational class changes and 7 per cent to new employment status coding. The latter was more likely to record the deceased as a supervisor than earlier systems. This had a particular impact on Classes 2 and 5 (lower managerial and professional and lower supervisory and technical), where the supervisor classification often raises the subject from the Intermediate or 
Semi-routine classes respectively. While the effect of such changes on a longitudinal study such as the current one are less than the numerator-denominator problems occurring for cross-sectional studies, the changes in classification rules at each census detract to some extent from the consistency of the results over time.

Any errors arising from the non-unique mapping between 1981 and 1991 occupation codes are not random. These are small however, as has been shown.

There was substantial social mobility over time, as denoted by sample members' own NS-SEC as measured in 1981 and 2001, for those who were at both censuses. While there is much evidence referenced in this paper, to suggest that early years have the greatest effect on health outcomes, subsequent employment and other experiences, including social mobility play a role in the accumulation of relative advantage and disadvantage (Marmot Review, 2010).

Immigrants and people who move frequently in and out of the country are under-represented in the analysis. Immigrants could only be assigned an NS-SEC class if they were present at a census. Therefore, many people, in particular those who entered the country since 2001, could not be assigned an occupation-based class.

The selection effect (referred to in the Discussion) may have depressed the range across the analytic classes in the first and possibly the second period analysed.

\section{Conclusions}

The analysis suggests that an approximation to NS-SEC for the 1981 Census can be constructed to produce a valid series of life expectancy by socio-economic class over time.

A clear social gradient persists over time, with remarkable consistency. The only minor exception is the relative ranking of Higher managers and Higher professionals for whom the ranking changed in one period, although Higher professionals were estimated to have the highest life expectancy in most periods. For men, the range from most to least advantaged class was approximately six years at birth and for women four years, both slightly less than the range when using the former occupation based measure of Registrar General's social class. For men, inequality appeared to increase from the mid-1980s and then to decrease slightly in the period 2002-06. However, it is too soon to say whether this represents a turning point for men. It is worth noting however, that the Routine class, the most disadvantaged of the classes whose members could be assigned by a current or former occupation, showed the second greatest improvement in life expectancy of all the classes in the most recent period.

For women there was no sign of a decline in inequality, either at birth or at age 65 . Women classified as lower professional or as self-employed or own account workers had the greatest increase in life expectancy since the mid-1980s.

Using the summary three-class NS-SEC the managerial and professional class had the highest life expectancy, and had experienced the greatest growth in life expectancy since the start of the study period. The reverse was the case for the Routine and manual class. The intermediate group tended to have life expectancy estimates closer to those for managerial and professional occupations than to those for routine and manual occupations. 
Comparison with the social class measure of life expectancy suggested that the range from highest to lowest exhibited less volatility from one period to the next using NS-SEC. Results obtained using the three-class condensed NS-SEC were broadly similar in range and pattern to those obtained using the non-manual and manual groupings for social class.

The degree of social mobility between 1981 and 2001 suggests that, while there were good reasons to adhere to the conventional early assignment of class as described in this article, further investigation should be made into a conditional revision of class of a sample member at the beginning of each decade, but structured to avoid the worst effects of health selection.

Owing to the difficulties involved in classifying people by occupation - especially for women, some of whom may have a weaker attachment to the labour market - other methods of classification are being sought. This study attempted a 'combined' measure for husbands and wives which attributed the most advantageous class for a couple, but this did not make a substantive difference to the results. It also does not reflect the range of modern family structures. Work on household-based measures and those which better reflect a person's more recent occupational status is continuing.

An alternative approach may be to investigate educational attainment rather than occupation as a proxy for social capital, but this too has associated problems.

Subject to consultation, the series - based on social class - which is being published simultaneously with this article will be discontinued and the NS-SEC series updated periodically.

\section{Acknowledgements}

This work is an extension of that first published by Lin Hattersley and developed by Peter Goldblatt, Angela Donkin, Kevin Lynch, Alec Ross, Bola Akinwale and Louisa Blackwell among others. The author has built upon the work of these people, but is obviously responsible for any errors in the current analysis. The author is also grateful for the support of various colleagues during the course of this work. 


\section{References}

Acheson D (1998) Independent inquiry into inequalities in health, The Stationery Office: London

Black D, Morris J, Smith C and Townsend P (1980) Inequalities in health: report of a research working group. Department of Health and Social Security: London. (P.358)

Blane D, Harding S and Rosato M (1999) 'Does social mobility affect the size of the socioeconomic mortality differential?: evidence from the Office for National Statistics Longitudinal Study.

Chiang C L (1968) 'Introduction to Stochastic Processes in Biostatistics', New York: John Wiley \& Sons, Inc., Chapter 9, pp 189-214

Corsini V (2010) ‘Highly educated men and women live longer’ Eurostat, Luxembourg

Department of Health (2010) Post-2010 strategic review of health inequalities (The Marmot Review)

Donkin A, Goldblatt P and Lynch K (2002) 'Inequalities in life expectancy by social class, 1972-99' Health Statistics Quarterly 15, 5-15. nswebcopy/StatBase/Product.asp?vInk=15342

Donkin A, Lee YH and Toson B (2002) 'Implications of changes in the UK social and occupational classifications in 2001 for vital statistics', Population Trends 107, 23-34

Elias P (1997) 'Social Class and the Standard Occupational Classification' in Rose D and O'Reilly $\mathrm{K}$ (eds) Constructing Classes - towards a new social classification for the UK, ESRC/ONS, Swindon

Erikson R (1984) 'Social class of men, women and families', Sociology, 18, 500-14

Fitzpatrick J (2003) 'Examining mortality rates by the NS-SEC using death registration data and the 1991 Census', in Rose D and Pevalin D (eds) A Researcher's Guide to the National Statistics Socio-economic Classification. SAGE Publications Ltd.

Fox A, Goldblatt P and Jones D (1985) 'Social class mortality differentials: artefact, selection or life circumstances?' Journal of Epidemiology and Community Health, 39, 1-8

Goldblatt P and Whitehead M (2000) 'Inequalities in health - development and change', Population Trends 100, 13-19

Goldthorpe J (1997) 'The Goldthorpe' Class Schema: some observations on conceptual and operational issues in relation to the ESRC review of government social classifications', in Rose D and O'Reilly K (eds) Constructing Classes: Towards a new social classification for the UK. Swindon: ESRC/ONS.

Hattersley L (1997), Expectation of life by social class in Drever F and Whitehead M (eds) Health Inequalities: Decennial Supplement Series DS No. 15, The Stationery Office: London

Johnson B and Blackwell $L$ (2007) 'Review of methods for estimating life expectancy by social class using the ONS Longitudinal Study' Health Statistics Quarterly 35, 28-36. 
Langford A and Johnson B (2009) 'Social inequalities in female mortality by the National Statistics Socio-economic Classification, England and Wales, 2001-03', Health Statistics Quarterly 42, 6-21

Langford A and Johnson B (2010) 'Trends in social inequalities in male mortality, 2001-08. Intercensal estimates for England and Wales'. Health Statistics Quarterly 47, 5-32.

Mackenbach J, Stirbu I, Roskam A-J, Schaap M, Menvielle G, Leinsalu M and Kunst A (2008) 'Socio-economic inequalities in health across 22 European Countries', New England Journal of Medicine, 358 2468-81

Office for National Statistics (2002) The National Statistics Socio-economic Classification. User Manual, on-line edition. Available on the Office for National Statistics website:

statistics.gov.uk/statbase/Product.asp?vlnk=13561\&Pos=1\&ColRank=2\&Rank=816

Office for National Statistics report (2007) 'Trends in Life Expectancy by social class 19722005'.Available on the Office for National Statistics website at: statistics.gov.uk/statbase/Product.asp?vlnk=8460

Office of Population Censuses and Surveys (1978) 'Occupational Mortality 1970-72. Decennial Supplement' Series DS no 1, HMSO

Office of Population Censuses and Surveys (1991) 'Standard Occupational Classification' Volume 3, London: HMSO

Power C, Hypponen E and Davey Smith G (2005) 'Socio-economic position in childhood and early adult life and risk of mortality: A prospective study of the mothers of the 1958 British Birth Cohort', American journal of Public Health 95, No 8 1396-1402

Rose D (1995) Official social classifications in the UK, Social Research Update, Issue 9, University of Surrey

Rose D and Pevalin D (Eds) (2003) A Researcher's Guide to the National Statistics Socioeconomic Classification. SAGE Publications Ltd.

Stata statistical software (Release 9) - Statacorp, College Station, TX, USA

White C, Edgar G and Siegler V (2008) 'Social inequalities in male mortality for selected causes of death by the National Statistics Socio-economic Classification, England and Wales, 2001-03', Health Statistics Quarterly 38, 19-31. Available on the Office for National Statistics website at: statistics.gov.uk/statbase/Product.asp?vlnk=6725

White C, Glickman M, Johnson B and Corbin T (2007) 'Social inequalities in adult male mortality by the National Statistics Socio-economic Classification, England and Wales, 2001-03', Health Statistics Quarterly 36, 6-23. Available on the Office for National Statistics website: statistics.gov.uk/STATBASE/Product.asp?vlnk=6725

White C, Wiggins R, Blane D, Whitworth A and Glickman M (2005) 'Person, place or time? The effect of individual circumstances, area and changes over time on mortality in men, 19952001', 
Health Statistics Quarterly 28, 18-26. Available on the Office for National Statistics website: statistics.gov.uk/STATBASE/Product.asp?vlnk $=6725$ 


\section{Appendix}

\section{Table A1a Life expectancy by NS-SEC class, males at birth, using a 'combined' classification}

England and Wales

Years

\begin{tabular}{cccccc}
\hline $1982-86$ & $1987-91$ & $1992-96$ & $1997-2001$ & $2002-06$ \\
\hline LE $95 \%$ & LE 95\% & LE 95\% & LE $95 \%$ & LE & LI \\
Cl & Cl & Cl & Cl \\
+/- & $+/-$ & $+/-$ & $+/-$ & $+/-$
\end{tabular}

At birth

Analytic classes
1. Higher managerial \& professional
1.1 Large employers \& higher managers
1.2 Higher professional
2 Lower managerial \& professional
3 Intermediate
4 Small employers \& own a/c workers
5 Lower supervisory \& technical
6 Semi-routine
7 Routine

Range highest- lowest

\section{Condensed NS-SEC}

Managerial \& professional

Intermediate

Routine \& manual

Range highest- lowest

Unclassified

All Men

$\begin{array}{ll}71.7 & 0.2\end{array}$

$\begin{array}{ll}71.0 & 0.4\end{array}$

3.9

$60.2 \quad 1.4$ $\begin{array}{ll}76.6 & 0.7\end{array}$

$\begin{array}{ll}75.5 & 1.0\end{array}$

$\begin{array}{ll}77.8 & 0.9\end{array}$

75.20 .6

$\begin{array}{ll}74.8 & 0.7\end{array}$

$\begin{array}{ll}74.2 & 0.8\end{array}$

$\begin{array}{ll}72.9 & 0.7\end{array}$

$\begin{array}{ll}72.0 & 0.6\end{array}$

70.40 .6

6.2

$\begin{array}{ll}74.9 & 0.5\end{array}$

$\begin{array}{ll}75.8 & 0.4\end{array}$

$\begin{array}{ll}74.5 & 0.5\end{array}$

$\begin{array}{ll}71.7 & 0.4\end{array}$

60.31 .2

$\begin{array}{ll}72.6 & 0.2\end{array}$

$\begin{array}{ll}73.8 & 0.2\end{array}$

$\begin{array}{ll}78.2 & 0.9\end{array}$

$\begin{array}{ll}76.3 & 0.5\end{array}$

$\begin{array}{ll}75.5 & 0.6\end{array}$

$\begin{array}{ll}75.3 & 0.8\end{array}$

$\begin{array}{ll}73.2 & 0.7\end{array}$

$\begin{array}{ll}72.1 & 0.6\end{array}$

$\begin{array}{ll}71.1 & 0.6\end{array}$

6.5
$80.4 \quad 0.6$

$\begin{array}{lll}76.9 & 0.9\end{array}$

$\begin{array}{ll}78.7 & 0.9\end{array}$

$\begin{array}{ll}79.9 & 0.9\end{array}$

$\begin{array}{ll}78.6 & 0.9\end{array}$

$80.7 \quad 0.8$

$\begin{array}{ll}77.8 & 0.5\end{array}$

$79.2 \quad 0.5$

$\begin{array}{ll}76.8 & 0.6\end{array}$

$\begin{array}{ll}77.9 & 0.7\end{array}$

$\begin{array}{ll}76.4 & 0.7\end{array}$

$\begin{array}{ll}77.7 & 0.8\end{array}$

$\begin{array}{ll}74.9 & 0.6\end{array}$

$\begin{array}{ll}76.4 & 0.7\end{array}$

$\begin{array}{ll}73.8 & 0.6\end{array}$

$\begin{array}{ll}74.9 & 0.6\end{array}$

$\begin{array}{ll}71.9 & 0.7\end{array}$

$74.4 \quad 0.6$

6.8

6.0

Source: ONS Longitudinal Study 


\section{Table A1b Life expectancy by NS-SEC class, males at age 65, using a 'combined' classification}

England and Wales

Years

\begin{tabular}{|c|c|c|c|c|c|c|c|c|c|}
\hline & \multicolumn{2}{|c|}{ 1982-86 } & \multirow{2}{*}{$\begin{array}{c}\text { 1987-91 } \\
\text { LE 95\% } \\
\mathrm{Cl}\end{array}$} & \multicolumn{2}{|c|}{ 1992-96 } & \multicolumn{2}{|c|}{$1997-2001$} & \multicolumn{2}{|c|}{ 2002-06 } \\
\hline & LE & $\begin{array}{c}95 \% \\
\mathrm{Cl}\end{array}$ & & LE & $\begin{array}{c}95 \% \\
\mathrm{Cl}\end{array}$ & LE & $\begin{array}{c}95 \% \\
\mathrm{Cl}\end{array}$ & LE & $\begin{array}{c}95 \% \\
\mathrm{Cl}\end{array}$ \\
\hline$+/-$ & & & $+/-$ & & $+/-$ & & $+/-$ & & $+/-$ \\
\hline
\end{tabular}

At age

Analytic classes

1. Higher managerial \& professional

1.1 Large employers \& higher managers

15.20 .6

15.90 .5

$16.6 \quad 0.5$

18.10 .5

$18.8 \quad 0.4$

$14.7 \quad 0.8$

15.10 .7

$\begin{array}{ll}16.2 & 0.7\end{array}$

17.90 .6

$18.6 \quad 0.6$

1.2 Higher professional

16.10 .8

$\begin{array}{ll}16.7 & 0.7\end{array}$

$\begin{array}{ll}17.1 & 0.7\end{array}$

18.20 .6

$19.0 \quad 0.6$

2 Lower managerial \& professional

$14.9 \quad 0.4$

$15.4 \quad 0.4$

$\begin{array}{ll}15.9 & 0.3\end{array}$

$\begin{array}{ll}17.0 & 0.3\end{array}$

$\begin{array}{ll}17.9 & 0.3\end{array}$

3 Intermediate

$13.9 \quad 0.4$

$\begin{array}{ll}15.0 & 0.5\end{array}$

$15.5 \quad 0.4$

16.20 .4

$17.4 \quad 0.4$

4 Small employers \& own a/c workers

$14.0 \quad 0.5$

$\begin{array}{ll}14.6 & 0.5\end{array}$

$15.4 \quad 0.5$

15.90 .5

17.30 .5

5 Lower supervisory \& technical

$13.3 \quad 0.4$

$13.3 \quad 0.4$

$14.3 \quad 0.4$

15.20 .4

16.20 .4

6 Semi-routine

$\begin{array}{ll}12.8 & 0.3\end{array}$

$\begin{array}{ll}13.3 & 0.3\end{array}$

$13.7 \quad 0.3$

14.50 .3

$15.6 \quad 0.4$

7 Routine

$12.8 \quad 0.3$

$\begin{array}{ll}12.9 & 0.3\end{array}$

13.20 .3

$\begin{array}{ll}13.7 & 0.3\end{array}$

$\begin{array}{ll}15.0 & 0.4\end{array}$

Range highest- lowest

2.4

3.0

3.4

4.4

3.8

\section{Condensed NS-SEC}

Managerial \& professional

Intermediate

Routine \& manual

$15.1 \quad 0.3$

$\begin{array}{ll}15.5 & 0.3\end{array}$

$16.2 \quad 0.3$

$\begin{array}{ll}17.4 & 0.3\end{array}$

$\begin{array}{ll}18.3 & 0.3\end{array}$

$13.9 \quad 0.3$

$14.8 \quad 0.3$

$15.5 \quad 0.3$

$\begin{array}{ll}16.1 & 0.3\end{array}$

$\begin{array}{ll}17.3 & 0.3\end{array}$

$12.9 \quad 0.2$

13.20 .2

$13.7 \quad 0.2$

14.40 .2

15.60 .2

Range highest- lowest

2.2

2.3

2.5

3.0

2.7

Unclassified

10.20 .4

11.20 .6

$\begin{array}{ll}12.0 & 0.7\end{array}$

14.20 .7

All Men

13.10 .1

$\begin{array}{ll}13.7 & 0.1\end{array}$

$14.5 \quad 0.1$

$\begin{array}{ll}15.5 & 0.1\end{array}$

$\begin{array}{ll}16.7 & 0.1\end{array}$

Source: ONS Longitudinal Study 


\section{Table A2a Life expectancy by NS-SEC class, females at birth, using a 'combined' classification}

England and Wales

Years

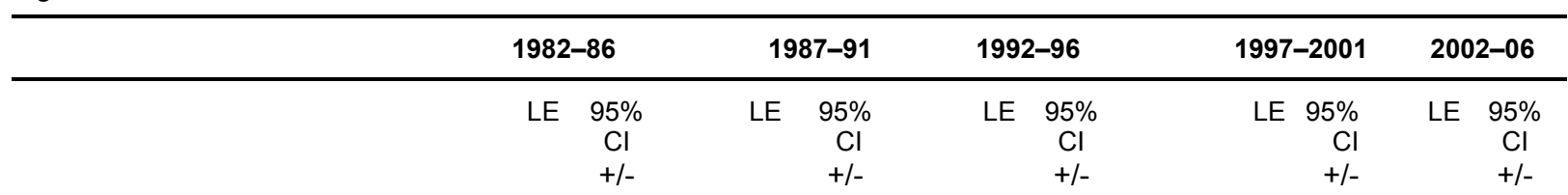

At birth

\section{Analytic classes}

1. Higher managerial \& professional

$\begin{array}{lllllllllll}81.2 & 1.0 & 82.4 & 0.8 & 83.0 & 0.8 & 82.8 & 0.6 & 84.3 & 0.6 \\ 80.5 & 1.6 & 83.0 & 1.3 & 83.2 & 1.1 & 82.4 & 1.0 & 83.7 & 0.9 \\ 82.0 & 1.4 & 82.2 & 1.1 & 82.7 & 1.1 & 83.1 & 0.9 & 84.9 & 0.8 \\ 79.9 & 0.7 & 81.1 & 0.6 & 81.2 & 0.5 & 82.1 & 0.5 & 83.3 & 0.4 \\ 79.7 & 0.7 & 80.8 & 0.7 & 81.1 & 0.6 & 81.1 & 0.6 & 82.0 & 0.6 \\ 79.3 & 0.9 & 80.1 & 0.9 & 80.7 & 0.8 & 80.9 & 0.7 & 82.2 & 0.8 \\ 78.6 & 0.9 & 78.4 & 0.7 & 79.7 & 0.7 & 79.7 & 0.6 & 80.5 & 0.7 \\ 77.7 & 0.7 & 77.7 & 0.6 & 78.6 & 0.6 & 79.0 & 0.6 & 80.0 & 0.6 \\ 76.4 & 0.7 & 76.9 & 0.7 & 77.4 & 0.6 & 77.9 & 0.7 & 79.0 & 0.6\end{array}$

Range highest- lowest

4.8

5.5

5.6

4.9

5.3

\section{Condensed NS-SEC}

Managerial \& professional

Intermediate

Routine \& manual

Range highest- lowest

Unclassified

All Women
80.30 .5

79.60 .6

77.40 .4

2.9

71.51 .1

$\begin{array}{lll}77.4 & 0.2\end{array}$

\begin{tabular}{ll}
$78.3 \quad 0.2$ \\
\hline
\end{tabular}

$\begin{array}{ll}79.2 & 0.2\end{array}$

$\begin{array}{ll}79.9 & 0.2\end{array}$

$81.1 \quad 0.2$

Source: ONS Longitudinal Study 


\section{Table A2b Life expectancy by NS-SEC class, females at age 65, using a 'combined' classification}

England and Wales

\begin{tabular}{ll}
\hline & \\
\hline Analytic classes \\
1. & Higher managerial \& professional \\
1.1 Large employers \& higher \\
managers \\
2.2 Higher professional \\
\hline 3 & Lower managerial \& professional \\
4 & Small employers \& own a/c workers \\
5 & Lower supervisory \& technical \\
6 & Semi-routine \\
7 & Routine
\end{tabular}

Range highest- lowest

3.0

3.7

3.74 .0

\section{Condensed NS-SEC}

\section{Managerial \& professional}

Intermediate

Routine \& manual

Range highest- lowest

Unclassified

$\begin{array}{ll}19.6 & 1.0 \\ 19.5 & 1.5 \\ 19.7 & 1.3 \\ 18.9 & 0.6 \\ 18.3 & 0.6 \\ 18.6 & 0.8 \\ 18.5 & 0.6 \\ 17.3 & 0.5 \\ 16.6 & 0.4\end{array}$

$20.3 \quad 0.7$

$20.8 \quad 1.3$

$20.1 \quad 0.9$

$19.6 \quad 0.5$

$19.3 \quad 0.5$

$\begin{array}{ll}18.8 & 0.7\end{array}$

$17.7 \quad 0.5$

$17.2 \quad 0.4$

$17.3 \quad 0.4$

$19.0 \quad 0.5$

$18.4 \quad 0.5$

$\begin{array}{lll}17.3 & 0.3\end{array}$

1.8

16.20 .2

16.

$19.7 \quad 0.4$

$\begin{array}{ll}19.8 & 0.3\end{array}$

19.10 .4

$19.4 \quad 0.4$

$17.4 \quad 0.2$

$17.9 \quad 0.2$

1.9

2.62 .8

All Women

Source: ONS Longitudinal Study $\begin{array}{ll}17.0 & 0.1\end{array}$

$17.5 \quad 0.1$ $\begin{array}{ll}20.5 & 0.3\end{array}$

$\begin{array}{ll}19.5 & 0.3\end{array}$

$\begin{array}{ll}17.9 & 0.2\end{array}$

2.4

$\begin{array}{ll}16.3 & 0.3\end{array}$

$16.6 \quad 0.4$

$\begin{array}{ll}21.3 & 0.3\end{array}$

$20.2 \quad 0.3$

$18.6 \quad 0.2$

$17.4 \quad 0.5$ 